\title{
Nonsense suppression position effect implicates poly(A)-binding protein in the regulation of translation termination
}

Chan Wu, Bijoyita Roy ${ }^{1}$, Feng He, and Allan Jacobson*

Department of Microbiology and Physiological Systems

University of Massachusetts Medical School

368 Plantation Street

Worcester, MA 01655

Running title: Pab1 regulates translation termination

Keywords: Nonsense codon, PTC, readthrough, poly(A), Pab1

*corresponding author

allan.jacobson@umassmed.edu

1-508-856-2442

Present address:

New England Biolabs

240 County Road

Ipswich, MA 01938 


\section{SUMMARY}

Readthrough of translation termination codons, also known as nonsense suppression, is a relatively inefficient process mediated by ribosomal $A$ site recognition and insertion of near-cognate tRNAs. Multiple factors influence readthrough efficiency, including nonsense codon specificity and context. To determine whether nonsense codon position in a gene influences the extent of readthrough, we generated a series of LUC nonsense alleles and quantitated both readthrough and termination efficiencies at each nonsense codon in yeast cells lacking nonsense-mediated mRNA decay (NMD) activity. Readthrough efficiency for premature termination codons (PTCs) manifested a marked dependence on PTC proximity to the mRNA 3'-end, decreasing progressively across the LUC ORF but increasing with 3'-UTR lengthening. These effects were eliminated, and translation termination efficiency decreased considerably, in cells harboring pab1 mutations. Our results support a critical role for poly(A)-binding protein in the regulation of translation termination and suggest that inefficient termination is the trigger for NMD. 


\section{INTRODUCTION}

Translation termination in eukaryotes is orchestrated by the release factors eRF1 and eRF3 when any of the three nonsense codons (UAA, UAG, or UGA) in an mRNA occupies the A site of a ribosome (Alkalaeva et al., 2006; Stansfield et al., 1995; Zhouravleva et al., 1995). eRF1 recognizes A site-localized nonsense codons and hydrolyzes peptidyl-tRNA, whereas eRF3 interacts with eRF1 and stimulates termination via its GTPase activity (Alkalaeva et al., 2006; Salas-Marco and Bedwell, 2004). eRF1 and near-cognate (nc) tRNAs, i.e., tRNAs capable of base-pairing with nonsense codons at two of the three standard codon positions, compete for binding to the ribosomal A site (Brown et al., 2015). Although this competition is inefficient, when successful it leads to insertion of an amino acid and continuation of translational elongation until the next inframe nonsense codon is encountered (Roy et al., 2016; Roy et al., 2015a). Such a bypass of translation termination is designated nonsense suppression or readthrough (Brenner et al., 1965; Keeling et al., 2014; Peltz et al., 2013).

Multiple factors appear to influence the competition between nc-tRNAs and eRF1, and hence the extent of nonsense suppression, including: a) the identity of the stop codon, with UGA promoting higher levels of readthrough than UAG or UAA (Howard et al., 2000; Loughran et al., 2014; Manuvakhova et al., 2000), b) the immediate context of a stop codon, with the highest readthrough levels typically occurring when adenine precedes and cytosine follows the stop codon (Bonetti et al., 1995; McCaughan et al., 1995; Mottagui-Tabar et al., 1998; Tork et al., 2004), c) specific sequences or structures 3' to the stop codon (Anzalone et al., 2019; Cridge et al., 2018; Harrell et al., 2002; Namy et al., 2001; Skuzeski et al., 1991), and d) the integrity of the release factors and the ribosome (Carnes et al., 2003; Chernoff et al., 1994; Liu and Liebman, 1996; Loenarz et al., 2014; Serio and Lindquist, 1999; Singleton et al., 2014; Velichutina et al., 2000). Another important determinant of readthrough efficiency may be the relative position of the stop codon within the open reading frame (ORF). Toeprinting experiments in yeast demonstrated that termination at premature termination codons (PTCs) is considerably slower than that at normal termination codons (NTCs) (Amrani et al., 2004). This difference predicts that readthrough should occur more readily at PTCs than at NTCs, an expectation borne out by results obtained when cultured cells, animals, or patients are 
treated with the readthrough-promoting drug ataluren (Hirawat et al., 2007; Welch et al., 2007) as well as by recent studies of non-canonical genetic codes in Ciliates (Heaphy et al., 2016; Swart et al., 2016; Zahonova et al., 2016).

These functional differences between PTCs and NTCs are consistent with the notion that the position of a PTC within an ORF may influence its susceptibility to readthrough and suggest that PTCs closest to the 3'-end of an ORF, i.e., those most likely to have NTC-like contexts, may be the least likely to have high efficiencies of readthrough whereas those more 5'-proximal are likely to have elevated readthrough efficiencies. Here, we have investigated the role of ORF position of PTCs in the regulation of readthrough in yeast. We constructed PTCS at six different positions of the firefly LUC ORF, expressed these alleles in yeast cells inactive for the nonsense-mediated mRNA decay (NMD) pathway, and assessed both readthrough and termination efficiencies at each ORF position by quantitating both the full-length protein and the premature termination products expressed from each PTC allele. Our results revealed a position-dependent effect for readthrough and termination efficiencies, and suggested that nonsense codon proximity to the mRNA 3'-end was an important determinant of termination efficiency. Consistent with earlier studies implicating a role for poly(A)-binding protein in the regulation of translation termination (Ivanov et al., 2016) we find that deletion of the yeast $P A B 1$ gene markedly reduces premature termination efficiency, thus yielding substantial enhancement of PTC readthrough.

\section{RESULTS}

\section{LUC reporters for readthrough assays}

To determine the extent of nonsense codon readthrough at different positions of an ORF we constructed a set of reporter genes with PTCs positioned at six locations within the firefly luciferase ( $L U C$ ) coding region (Figure 1A). Each of these constructs has a stop codon at a designated position, a 3X-HA tag at the ORF N-terminus to facilitate the detection of premature termination products, and a StreplI-FLAG (SF) tag at the ORF C-terminus to facilitate the detection of full-length readthrough protein. Each individual LUC cassette was cloned into the pRS315 yeast centromere vector, flanked by the 
promoter region, 5'-UTR, and 3'-UTR of the yeast TPI1 gene, and then transformed into WT and upf1 $\Delta$ cells to assess expression of the Luc protein. To increase the generation of full-length readthrough products, we used a weak terminator (UGA CAA) (Bonetti et al., 1995) for each PTC reporter while including a strong terminator (UAA) in the normal termination codon (NTC) position. As controls, an NTC reporter (lacking any nonsense codons in the coding region) and an empty vector were also transformed into WT and upf1 $\Delta$ cells.

\section{PTC readthrough efficiency decreases across the LUC ORF}

To compare the efficacy of PTC readthrough at different positions of the LUC ORF, cells harboring the respective LUC alleles were grown, harvested, and analyzed in parallel. Relative readthrough efficiencies (Figures 1D, E) were determined by normalizing western blotting results with anti-FLAG antibodies (Figure 1B, upper panel) to the level of an internal control protein (Pgk1) in the same samples (Figure 1B, lower panel) and to the level of LUC mRNA in each sample (determined by northern blotting, and also normalized to a control RNA, SCR1; Figure 1C). In WT cells, the levels of fulllength readthrough protein obtained from the early PTC alleles, PTC20, PTC41, and PTC160, were comparably low, whereas those obtained from the middle PTCs, PTC386 and PTC460, were approximately 1.5- to 2-fold higher (Figure 1B, left, upper panel; Figure 1D, left panel). That obtained with the late PTC, PTC520, was the lowest of the set. Every PTC allele in WT cells showed readthrough levels of luciferase that were less than 1\% of the level obtained from the WT LUC allele (LuC-wt) (Figure 1B, upper panel).

Upf1 is a key regulator of NMD, and deletion of its gene not only stabilizes nonsense-containing mRNAs, but also enhances nonsense codon readthrough and inactivates the degradation of prematurely terminated polypeptides ( $\mathrm{He}$ and Jacobson, 2015; Johansson and Jacobson, 2010; Kuroha et al., 2009; Leeds et al., 1991). Accordingly, to augment detection of readthrough products, and to minimize mRNA variability as a potential complication, we repeated the same experiments in upf1 $\Delta$ cells. The extent of readthrough in upf1 $\Delta$ cells was highest when a PTC was proximal to the $\mathrm{N}$ terminus of the LUC ORF (PTC20 and PTC41 showed 2\% of LuC-wt) and diminished progressively as the PTC positions approached the C-terminus of the ORF (Figure 1B, 
upper panel). After normalizing to LUC mRNA levels (Figure 1C), the relative readthrough efficiencies of PTCs in upf1 $\Delta$ cells showed a clear position effect in which readthrough efficiency decreased across the LUC ORF (Figures 1D, E). These variations in readthrough efficiency were not likely to be attributable to differences in the stability of the respective full-length readthrough proteins (Kuroha et al., 2009) because treating the cells with the proteasome inhibitor MG132 did not alter the trend of the readthrough proteins across the ORF (Figures S1A, B).

In parallel with our western blotting assays for full-length readthrough proteins we also employed western blotting with anti-HA antibodies to detect prematurely terminated polypeptides originating from each PTC allele. These products were readily detected from PTC160, PTC386, PTC460, and PTC520 (Figure 1B, middle panel, and Figure S1A, middle panel; see red asterisks). Corrected for the Pgk1 control protein and mRNA levels, the recovery of prematurely terminated polypeptides in upf1 $\Delta$ cells showed a general upward trend from PTC160 to PTC460, a result consistent with our observation of decreased readthrough across the same region of the LUC ORF (Figure S2A and B, left panels). Further, our inability to detect any premature termination products from the PTC20 and PTC41 alleles expressed in WT and upf1 $\Delta$ cells was not likely to be due to their failure to be recovered by western blotting. This conclusion follows from an experiment in which we synthesized a polypeptide containing the 3X-HA epitope and the first 19 amino acids of luciferase (i.e., the polypeptide that would be generated by premature termination at PTC20), mixed it with a lysate from cells expressing PTC20, and subjected the sample to our western blotting procedure. Figure S1C shows that this peptide could be detected.

\section{Alterations of LUC mRNA 3'-UTR lengths correlate with changes in relative readthrough efficiencies}

Earlier studies have suggested that interactions between mRNA-associated poly(A)-binding protein (Pab1 in yeast) and the release factor eRF3 enhance translation termination efficiency (Amrani et al., 2004; Heaphy et al., 2016; Ivanov et al., 2016; Roque et al., 2015; Swart et al., 2016; Zahonova et al., 2016). To test whether the progressive reduction in LUC PTC readthrough efficiencies we observed in upf1 cells reflects 
changes in PTC proximity to Pab1 (or any other 3'-UTR-localized regulatory factor), we began with the reporter manifesting the least efficient readthrough (LUC-PTC520) and generated a set of deletions in the TPI1 fragment of that gene that encodes its 3'-UTR (Figure 2A). The reporters harboring these deletions were then transformed into upf1 $\Delta$ cells and the effects of the deletions on PTC readthrough efficiencies were determined as in Figure 1. Western blotting with anti-FLAG antibodies indicated that the level of fulllength readthrough protein obtained from the $\Delta 101-298$ and $\Delta 201-298$ alleles remained similar to that of the LUC-PTC520 allele, but increased in the samples obtained from the $\Delta 1-99, \Delta 1-198$, and $\Delta F L$ alleles (Figure 2B, upper panel). After normalization to the Pgk1 control protein and the mRNA levels of each sample, we saw a 5-6-fold increase in the relative readthrough efficiencies of the mRNAs derived from the $\Delta 1-99, \Delta 1-198$, and $\Delta F L$ alleles (Figure 2C).

Northern blotting of the mRNAs expressed by each of the 3'-UTR deletion alleles revealed that the transcripts generated by the $\Delta 1-99, \Delta 1-198$, and $\Delta F L$ alleles were significantly longer than that derived from the original LUC-PTC520 allele (Figure 2B lower panel), suggesting that these alleles are commonly defective in TPI1 3'-UTRmediated cleavage/polyadenylation and most likely use alternative cryptic polyadenylation signals in the downstream vector sequences for mRNA formation. Consistent with this idea, our 3'-RACE and sequencing analyses indicated that transcripts generated from the LUC-PTC520 allele terminate within the TPI1 3' fragment at a single site that is $75 \mathrm{nt}$ downstream of the LUC ORF, whereas transcripts generated from the $\Delta 1-99, \Delta 1-198$, and $\Delta F L$ alleles all terminate within the vector at a site that is more than $600 \mathrm{nt}$ downstream of the LUC ORF (data not shown). To determine whether the observed enhancement of readthrough by the $\Delta 1-99, \Delta 1-198$, and $\Delta F L$ alleles is due to the increased length of their 3'-UTRs or to loss of putative positive 3'-UTR regulatory elements involved in translation termination we constructed an additional set of LUCPTC520 reporters that harbored small deletions in the gene's 3'-UTR (Figure 3A). These alleles were transformed into upf1 $\Delta$ cells and their expression was monitored by western and northern blotting as above. The two LUC-PTC520 alleles harboring small deletions in the TPI1 3'-UTR, $\triangle 1-24$ and $\Delta 25-50$, produced mRNAs similar in length to that from the original LUC-PTC520 allele, and these two alleles also had similar levels of full-length 
readthrough products and readthrough efficiencies as the LUC-PTC520 allele (Figures 3B and C). In contrast, the LUC-PTC520 allele harboring a large deletion in the TPI1 3'UTR, $\Delta 1-50$, produced mRNAs that included a longer isoform than that from the LUCPTC520 allele, and this allele had a significantly higher level of full-length readthrough product and readthrough efficiency than the LUC-PTC520 allele (Figures 3B and C). Since the increased readthrough efficiency of the $\Delta 1-50$ allele was not matched by either the $\Delta 1-24$ or the $\Delta 25-50$ allele (Figure $3 C$ ) it is likely that the principal readthroughenhancing consequences of the $\Delta$ 1-50 deletion are attributable to 3'-UTR lengthening.

\section{3'-UTR length, but not a specific sequence element, regulates the efficiency of PTC readthrough}

As noted above, increased PTC readthrough efficiencies of LUC-PTC520 reporters appear to correlate with lengthened 3'-UTRs. To further address this possibility, we carried out two additional experiments. In the first, we tested whether shortening of a long 3'-UTR by inserting a strong polyadenylation signal upstream of the cryptic polyadenylation site can diminish the PTC readthrough efficiency associated with that transcript. Based on the $\Delta$ 1-99 allele from Figure 2, we constructed two LUC-PTC520 alleles that lack the original TPI1 3'-UTR, but contain different sequences from the TPI1 3' region (i.e., from nt 100 to 199 or 100 to 298) with a strong polyadenylation signal from the GAL7 gene (Bucheli, He et al. 2007) inserted within the TPI1 3' sequences (Figure 4A). We designated these two constructs as $S$ and $L$ alleles and expected each of these alleles to produce transcripts with 3'-UTR lengths of about $75 \mathrm{nt}$. The S and L 3'-UTR reporters were transformed into upf1 $1 \Delta$ cells and western and northern analyses were used to monitor their expression as above. Northern blotting showed that the size of the LUC mRNAs generated from both alleles was now comparable to that derived from the original LUC-PTC520 allele (Figure 4B). Further, the elevated PTC readthrough efficiency resulting from a lengthened 3'-UTR ( $\triangle 1-99$ allele) was reduced to the level of the $L U C$ PTC520 FL allele (Figure 4B, C).

In the second experiment we tested directly the effects of 3'-UTR length on PTC520 readthrough efficiency. We made use of the LUC PTC520 $\triangle F L$ allele from Figure

2 and constructed a series of LUC PTC520 alleles that lacked a TPI1 3'-UTR by inserting 
the $G A L 7$ polyadenylation signal at different positions in the vector sequences downstream of the LUC ORF (Figure 5A). Transcripts generated from these LUC PTC520 alleles lack any TPI1 3'-UTR sequences, but contained different sequences in their 3'UTRs with lengths ranging from 60 to 600nt. Quantitation of the expression of these alleles in upf1 $1 \Delta$ cells showed that the level of full-length readthrough protein and the relative readthrough efficiencies increased progressively with 3'-UTR length (Figures 5B and C). Collectively, the results of Figures 2-5 indicate that the length of the 3'-UTR associated with the LUC mRNA plays an important cis-acting role in regulating translational readthrough of PTCs in yeast.

\section{Poly $(A)$ binding protein restricts PTC readthrough and maintains the PTC position effect}

In light of the correlation between 3'-UTR length and PTC readthrough seen in Figures 2-5 we sought to test directly whether the observed readthrough phenotypes reflected PTC proximity to $\mathrm{mRNA}$-associated Pab1 protein. PAB1 is an essential gene in yeast (Sachs et al., 1986; Sachs et al., 1987), but its absence can be studied in several suppressor mutants. Pbp1 was identified as a Pab1-interacting protein and pbp1 $\Delta$ cells suppress a pab1 $\Delta$ allele without having significant effects on mRNA translation or decay (Kato et al., 2019; Mangus et al., 1998a; Yang et al., 2019). Accordingly, we generated pab1 1 pbp1 $\Delta$ upf1 $\Delta$ yeast cells and transformed them with the pRS316-LUC-PTC reporters and control plasmids equivalent to those analyzed in the experiments of Figure 1. As additional controls, each of these reporters was also transformed into pbp1 $\Delta$ upf1 $\Delta$ cells. Readthrough efficiencies of the LUC-PTC reporters were determined in upf1 $\triangle$, pbp1 $\Delta$ upf1 $\Delta$, and pab1 $\Delta$ pbp1 $\Delta$ upf1 $\Delta$ cells and the results of these analyses are shown in Figure 6. Consistent with previous conclusions about the modest impact of the pbp1 $\Delta$ allele on mRNA translation and decay, we found the relative readthrough efficiencies of LUC-PTC reporters in pbp1 $\Delta$ upf $1 \Delta$ cells to be quite similar to those seen in upf $1 \Delta$ cells (Figure 6C). However, in pab1 $\Delta$ pbp1 $\Delta$ upf1 $\Delta$ cells the relative readthrough efficiencies of all LUC-PTC reporters were much higher than in upf1 $\Delta$ or pbp1 $\Delta$ upf1 $\Delta$ cells (Figure 6C), with readthrough efficiencies of PTC20, PTC41, PTC160, PTC386, PTC460, and

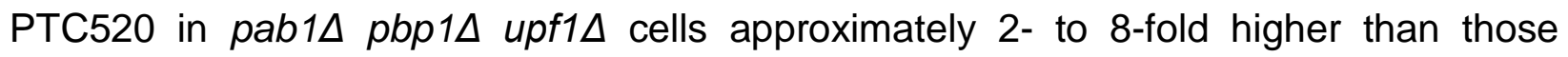


observed in the two other strains. Whereas readthrough efficiencies across the LUC ORF in upf1 $\Delta$ cells continuously decreased as the ribosome progressed from 5' to 3', in pab1 $\Delta$ pbp1 1 upf1 cells this gradient was absent and was replaced by a bell-shaped distribution of readthrough activity across the ORF. Further, in contrast to the increased levels of the LUC readthrough proteins (Figure 6A, upper panel), the premature termination products were much lower in pab1 $\Delta$ pbp1 $\Delta$ upf1 $\Delta$ cells than in upf1 $\Delta$ or pbp1 $\Delta$ upf1 $\Delta$ cells (Figure $6 \mathrm{~A}$, middle panel), with several premature termination products beyond detection in pab1 $\Delta$ pbp1 $\Delta$ upf1 $\Delta$ cells. Although termination efficiencies of LUCPTCs in pab1 1 pbp $1 \Delta$ upf1 $\Delta$ cells could not be quantitated, those in pbp $1 \Delta$ upf1 $\Delta$ cells could and they were found to be 1.5 to 2 -fold lower than those in upf1 $\Delta$ cells (Figure S2A).

The results of Figure 6 demonstrate that Pab1 restricts PTC readthrough in vivo. To begin to assign that function to specific $\mathrm{Pab} 1$ domains we examined the consequences of deleting the C-terminal domain of the protein, a deletion that does not impair yeast cell viability (Sachs et al., 1987). We constructed pab1 $\Delta C$ upf1 $\Delta$ cells, transformed them with the of LUC-PTC and control reporters, and evaluated PTC readthrough efficiency in these cells. Figure 7A (top panel) shows that the yields of full-length proteins from all six LUC$P T C$ reporters in pab1 $\triangle C$ upf1 $\Delta$ cells were higher than in upf1 $\Delta$ cells. After correction for protein and mRNA controls (Figures 7A, lower panel, and 7B), the relative readthrough efficiencies of PTCs in pab1 $\Delta C$ upf1 $\Delta$ cells were 2- to 4-fold higher than those of the same alleles in upf1 $\Delta$ cells (Figure $7 C$ ). Readthrough efficiencies in pab1 $\Delta C$ upf1 $\Delta$ cells were "flat" across the first two-thirds of the LUC ORF, but decreased for the last two alleles. Although premature termination products were detectable in pab1 $\Delta C$ upf1 $\Delta$ cells, their termination efficiencies were lower than those of upf1 $\Delta$ cells or pbp1 $\Delta$ upf $1 \Delta$ cells (Figure S2B).

\section{DISCUSSION}

\section{A PTC position effect in the LUC ORF is associated with variations in the efficiency of translation termination}

In experiments that established the colinearity of genes and their encoded polypeptide chains Sarabhai et al. (1964) also substantiated the prediction of Crick et al. 
(1961) that nonsense codons promoted the termination of protein synthesis. Initially, the only exceptions to the chain terminating effects of nonsense codons were observed in strains or extracts of E. coli expressing suppressor tRNAs (Andoh and Ozeki, 1968; Capecchi and Gussin, 1965; Engelhardt et al., 1965), but it eventually became clear that nonsense codon "readthrough" without suppressor tRNA intervention could be detected in numerous mRNAs of diverse species (Dunn et al., 2013; Eswarappa et al., 2014; Jungreis et al., 2011; Klagges et al., 1996; Loughran et al., 2014; Namy et al., 2003; Namy et al., 2002; Robinson and Cooley, 1997; Schueren et al., 2014; Steneberg and Samakovlis, 2001; Stiebler et al., 2014; Weiner and Weber, 1971). However, even with this considerable history, the mechanisms regulating nonsense codon readthrough remain poorly understood. Here, we demonstrate that in yeast upf1 $\Delta$ cells the position of a PTC in the LUC ORF dictates its readthrough efficiency such that a PTC proximal to the 5'-end of the ORF has -twofold higher readthrough efficiency than that of a PTC proximal to the 3'-end of the ORF (Figures 1B, upper panel, and 1E). Further, in parallel with a consistent reduction in readthrough efficiency from the beginning to the end of the LUC ORF, termination efficiency largely appeared to increase (Figures 1B, 6A, 7A, and S2). This position dependence of nonsense codon function is reminiscent of the noncanonical genetic code utilization in some species of protozoa, e.g., C. magnum, Parduczia sp., and Blastocrithidia sp., in which all three nonsense codons function as sense codons unless they are located near ORF 3'-ends, where they can still serve their usual termination function (Heaphy et al., 2016; Swart et al., 2016; Zahonova et al., 2016). The decoding of UAA, UAG, and UGA in these atypical genetic codes appears to be mediated in part by mutations that lessen the specificity of the release factor eRF1 and make it an ineffective competitor with tRNAs capable of nonsense codon recognition (Swart et al., 2016). The enhanced specificity of the same eRF1 molecules when ribosomes are translating near the end of ORFs is postulated to arise from proximity to 3'-end-associated poly(A)-binding protein and its stimulatory effects on eRF3, the release factor that normally augments eRF1 function (Swart et al., 2016). As discussed below, poly(A)-binding protein also appears to be a critical regulator of the LUC PTC position effects in yeast. 


\section{Yeast Pab1 is a key determinant of the PTC position effect}

The results of two different experimental approaches described here both implicate a role for poly $(\mathrm{A})$-binding protein (Pab1 in yeast) in the regulation of LUC PTC readthrough. First, we observed an inverse correlation between the extent of readthrough at a given PTC and the distance of that PTC from the mRNA 3'-end, i.e., the position of the poly $(A)$ tail. This was true for PTCs at different positions of the LUC ORF (Figure 1), as well as for PTC520 when it was associated with 3'-UTRs of different lengths (Figures 2-5). Consistent with these readthrough results was a trend toward higher efficiencies of translation termination as PTCs approached the ORF 3'-end (Figures 1B, 7A, S1A, and S2). Collectively, these position effects indicate that the efficiency of termination of LUC mRNA translation increases, and readthrough consequently decreases, as a ribosome approaches the mRNA 3'-end. While these results only provide indirect evidence implying a role for Pab1 in termination regulation a second set of experiments provided direct evidence for that role. Figure 6 shows that deletion of the PAB1 gene leads to large increases in readthrough efficiency at all PTC positions, comparably large reductions in termination efficiency, and loss of the progressive PTC position effects across the LUC ORF. Further, the experiments of Figure 6 demonstrate that the $p b p 1 \Delta$ mutation required for the maintenance of viability in pab1 $\Delta$ cells does not contribute to these effects.

A role for Pab1 in restricting readthrough is consistent with several earlier studies in multiple systems, including those reporting: a) position dependence of the noncanonical genetic codes in Ciliates (alluded to above) (Heaphy et al., 2016; Swart et al., 2016; Zahonova et al., 2016), b) interactions between eRF3 and PABP from mammalian, Xenopus, and yeast cells, and identification of specific interacting domains in the respective proteins, using two-hybrid, co-immunoprecipitation, isothermal titration calorimetry, and surface plasmon resonance methodologies (Cosson et al., 2002a; Cosson et al., 2002b; Hoshino et al., 1999; Hosoda et al., 2003; Jerbi et al., 2016; Kononenko et al., 2010; Roque et al., 2015; Uchida et al., 2002), and c) direct stimulation of peptidyl-tRNA hydrolysis dependent on eRF3:PABP interaction in a reconstituted cellfree system (Ivanov et al., 2016). However, our results differ from those of Roque et al. who found that readthrough efficiency in a dual luciferase assay in yeast decreased when Pab1:eRF3 interaction was interrupted (Roque et al., 2015). In addition to the use of 
different readthrough reporters a significant difference between our study and that of Roque et al. that may account for this difference was their inclusion of suppressor-tRNA in the strains being tested, i.e., their assays focused on the strong but artificial readthrough signals generated by a cognate suppressor tRNA whereas ours addressed the competition between eRF1 and near-cognate tRNAs that is typical of conventional PTC readthrough (Roy et al., 2016; Roy et al., 2015a).

\section{The inefficiency of premature termination may define susceptibility to NMD}

Although the focus of this study has been the possible role of Pab1:eRF3 interaction in the regulation of translation termination efficiency our results also have important implications for NMD. Earlier work on NMD in yeast showed that: a) PTCs within the first half to two-thirds of an ORF triggered NMD whereas those in the latter part of an ORF had little to no mRNA destabilizing effects (Hagan et al., 1995; Hennigan and Jacobson, 1996, 1997; Peltz et al., 1993; Peltz et al., 1994; Peltz and Jacobson, 1993), b) these PTC position effects in NMD could be mimicked and manipulated by shortening or lengthening mRNA 3'-UTRs (Amrani et al., 2004; Kebaara and Atkin, 2009; Muhlrad and Parker, 1999), and c) NMD could be antagonized by tethering Pab1 or eRF3 proximal to a PTC (Amrani et al., 2004). Indeed, these results, and toeprinting experiments showing that termination at PTCs was considerably slower than that at NTCs (Amrani et al., 2004), led to formulation of the faux-UTR model for NMD which postulated that the inefficient termination occurring at PTCs distant from an mRNA's bound Pab1 allowed for mRNA binding of the Upf factors that trigger NMD (Amrani et al., 2006a; Amrani et al., 2004; Amrani and Jacobson, 2006; Amrani et al., 2006b). Although almost all of the experiments here were carried out in NMD-deficient cells, the position effect of PTCs on NMD susceptibility of the LUC mRNA was evident in Figure 1C (compare WT to upf1 $\Delta$ ), is consistent with earlier published results, and, together with the data in Figures 1-7, indicates that termination deficiencies at PTCs are independent of Upf1 and, presumably, Upf2 and Upf3. Collectively, the results reported here and the earlier data supporting the faux-UTR model strongly suggest that inefficient termination is the trigger for NMD, possibly because the ribosome is transiently in a state that allows association of the Upf factors (He and Jacobson, 2015). 


\section{STAR METHODS}

\section{Yeast strains and plasmids}

Yeast strains used in this study have the W303 background and are listed in the table of Key Resources. The wild-type (WT) strain and its isogenic upf1 $\Delta$ derivative were described previously (He et al., 1997). Strains combining additional deletions with upf1 $\Delta$,

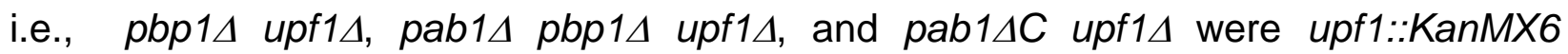
derivatives of yDM146, yDM206, and YAS2239 (Kessler and Sachs, 1998; Mangus et al., 1998b) and were constructed by PCR-mediated strategies with pFA6a-KanMX6 as the template (Longtine et al., 1998). Fragments amplified by the primer pair upf1-KanMX6-F and upf1-KanMX6-R were transformed into respective yeast strains by the high-efficiency method (Schiestl and Gietz, 1989). Each of the genomic DNA deletions was confirmed by PCR analysis with the oligonucleotide pair upf1-SF and upf1-SR.

All of the plasmids and oligonucleotides used in this study are listed in Supplementary Tables 1 and 2. The plasmid pRS315-LUC was subcloned from plasmid YEplac181-HA-LUC-SF (Roy et al., 2015b) as follows: First, a Pstl-Xbal fragment was isolated from YEplac181-HA-LUC-SF and cloned into pRS315 vector digested by Pstl/Xbal. Then, a TPI1 3'-UTR fragment was amplified from YEplac181-HA-LUC-SF by the primer pair of TPI13U-F(Xbal)/TPI13U-R(Notl), digested by Xbal/Notl, and ligated into pRS315-TPI1 promoter-3X-HA-LUC-StrepII-FLAG digested by Xbal/Notl.

The pRS315-LUC-PTCs were generated by overlap PCRs using a common outside primer pair, TPI1-promoter-F (Pst)/TPI13U-R (Notl), and an internal primer pair that introduced PTCs at specific codons: codon 20 (LUC-PTC20-F/R), codon 41 (LUCPTC41-F/R), codon 160 (LUC-PTC160-F/R), codon 386 (LUC-PTC386-F/R), codon 460 (LUC-PTC460-F/R), and codon 520 (LUC-PTC520-F/R). In each case, the final PCR products were digested by Pstl/Notl and cloned into pRS315 digested by Pst//Notl.

pRS315 plasmids containing LUC-PTC520- $\Delta 1-99,-\Delta 1-198,-\Delta 101-298,-\Delta 201-298$, $-\Delta 1-24,-\Delta 25-50,-\Delta 50$, and -L alleles were constructed by direct PCR of specific TPI1 3' regions using primer pairs of TPI3U-100-F(Xbal)/TPI13U-R(Notl), TPI3U-200F(Xbal)/TPI13U-R(Notl), TPI13U-F(Xbal)/ TPI3U-100-R(Notl), TPI13U-F(Xbal)/ TPI3U200-R(Notl), TPI3U-25-F(Xbal)/TPI13U-R(Notl), TPI3U-2550-F(Xbal)/TPI13U-R(Notl), 
TPI3U-50-F(Xbal)/TPI13U-R(Notl), and 200L-F(Xbal)/TPI13U-R(Notl), respectively. In each case, the PCR fragment digested by Xbal/Notl was used to replace the TPI1 3' fragment in pRS315-LUC-PTC520. pRS315 plasmids containing LUC-PTC520-S and LUC-PTC520-3U60 were generated by ligating the annealed DNA fragments of oligo pairs 100S-F/100S-R and GAL7-3U-F/GAL7-3U-R directly into pRS315-LUC-PTC520 digested by Xbal/Notl, respectively.

pRS315 plasmids containing LUC-PTC520-3U120, -3U200, -3U300, -3U400, 3U500, and -3U600 were all constructed by overlap PCRs in two steps. First, using a common outside primer pair (RS315-F-Sall/RS315-R-KasI) and a specific internal primer pair (3U120-F/3U120-R, 3U200-F/3U200-R, 3U300-F/3U300-R, 3U400-F/3U400-R, 3 U500-F/3U500-R, and 3U600-F/3U600-R), we generated a set of pRS315 vectors with a GAL7 polyadenylation signal (Bucheli et al., 2007) inserted at different locations of the $1 \mathrm{~kb}$ Sall-Kasl fragment. Second, a Pstl-Xbal fragment was isolated from pRS315-LUCPTC520 and ligated into this set of modified pRS315 vectors digested by Pstl/Xbal. This set of LUC-PTC520-xxUTR alleles from pRS315 plasmids generates transcripts with 3'UTR lengths ranging from 120 to $600 \mathrm{nt}$.

pRS316 plasmids containing LUC or LUC-PTC alleles were constructed in two steps. First, a HindIII-Xbal DNA fragment was isolated from the respective pRS315-LUC or LUC-PTC plasmids and cloned into pRS316. Then a Xbal-Notl fragment containing the TPI1 3' region was cloned downstream of the LUC or LUC-PTC ORF.

pRS315 derived plasmids were transformed into WT or upf1 $\triangle$ yeast, and pRS316 derived plasmids were transformed into pab1 $\Delta$ pbp1 $\Delta$ upf1 $\Delta$ or pbp $1 \Delta$ upf $1 \Delta$ yeast cells by the high-efficiency method (Schiestl and Gietz, 1989).

\section{Cell growth and western analysis}

Cells were grown in $25 \mathrm{ml}$ of synthetic complete (SC) media lacking leucine or uracil at $30^{\circ} \mathrm{C}$ to an optical density at $600 \mathrm{~nm}\left(\mathrm{OD}_{600}\right)$ of 0.7 . For each culture expressing a specific $L U C$ or LUC-PTC allele, $10 \mathrm{OD}_{600}$ units were harvested for western analysis and $4 \mathrm{OD}_{600}$ units from the same culture were collected for RNA extraction. Cell pellets for western analyses were resuspended in $110 \mu \mathrm{l}$ RIPA buffer $(25 \mathrm{mM}$ Tris-HCl pH 7.4, $150 \mathrm{mM} \mathrm{NaCl}, 1 \% \mathrm{NP}-40,1 \mathrm{mM}$ EDTA, 5\% glycerol) with 1mM PMSF and 1X protease 
inhibitor mixture (Thermo Scientific, \#A32965). The cell suspensions were lysed by vortexing for $30 \mathrm{sec}$ with $0.1 \mathrm{~g}$ pre-washed glass beads (Sigma-Aldrich, \#8772), followed by $30 \mathrm{sec}$ on ice, for 8 cycles. The lysates were centrifuged at $12,000 \mathrm{rpm}$ for $15 \mathrm{~min}$ in a Sorvall Legend $\mathrm{X} 1 \mathrm{R}$ centrifuge, at $4^{\circ} \mathrm{C}$. Aliquots $(90 \mu \mathrm{l})$ of the supernatants were mixed with Laemmli's SDS-sample buffer (Boston BioProducts, \#BP-110R) followed by boiling for $5 \mathrm{~min}$. The samples were then resolved by 10\% SDS-PAGE, transferred to ImmobilonP membrane (Millipore, \#IPVH0010), and incubated with anti-HA antibodies (SigmaAldrich, \#H3663, 1:2,000), anti-FLAG antibodies (Sigma-Aldrich, \#F7425, 1:1,000 or SANTA CRUZ, \#sc-51590, 1:100), or anti-Pgk1 antibodies (Thermo Fisher, \#459250, 1:4,000) overnight at $4^{\circ} \mathrm{C}$. The membrane was washed with PBST for $7 \mathrm{~min}, 3$ times, then incubated with anti-Mouse secondary antibodies (Thermo Fisher, \#A24506, 1:5,0001:10,000) or anti-Rabbit secondary antibodies (Sigma-Aldrich, \#GENA934, 1:5,000) for $45 \mathrm{~min}$ at RT. Then the membrane was washed with PBST for 7 min, 3 times. Proteins were detected using ECL reagents and Hyperfilm ECL (GE, \#28906835). The signal was analyzed with MultiGauge software.

\section{RNA preparation and northern analysis}

Total RNA from cell pellets was isolated as described previously (Herrick et al., 1990). Briefly, pellets were resuspended in $500 \mu \mathrm{l}$ buffer A (50 mM NaOAc pH5.2, $10 \mathrm{mM}$ EDTA, 1\% SDS, 1\% DEPC), extracted with $500 \mu$ I RNA-phenol (phenol saturated with 50 mM NaOAc pH5.2, 10 mM EDTA) by vortexing for $10 \mathrm{sec}$, followed by $50 \mathrm{sec}$ incubation in a $65^{\circ} \mathrm{C}$ water bath, for 6 cycles. Tubes were centrifuged at 12,000rpm in an Eppendorf 5417C centrifuge for $10 \mathrm{~min}$ at RT. The aqueous layers were recovered and followed by another phenol extraction. Phenol/chloroform $(500 \mu \mathrm{l})$ was added to the recovered aqueous layer, and the mixture was vortexed for 2 min at RT followed by 10 min centrifugation at $12,000 \mathrm{rpm}$. The aqueous layers were recovered and subjected to another phenol/chloroform extraction. The RNAs were precipitated by adding $40 \mu \mathrm{l}$ $\mathrm{NaOAc}(3 \mathrm{M}, \mathrm{pH} 5.2)$ and $1 \mathrm{ml}$ ethanol and incubated for 2 hours at $-80^{\circ} \mathrm{C}$. Tubes were centrifuged at $12,000 \mathrm{rpm}$ for $15 \mathrm{~min}$ at $4^{\circ} \mathrm{C}$. Pellets were washed with $70 \%$ ethanol and re-dissolved in $50 \mu \mathrm{l}$ RNase free distilled water. Aliquots (15 $\mu \mathrm{g})$ of each RNA sample were loaded onto a 1\% agarose/formaldehyde/MOPS gel and electrophoresed, blotted, 
and hybridized as described previously (He and Jacobson, 1995). Random-primed DNA probes made from Ncol-Xbal LUC fragments were used to detect HA-LUC-SF mRNAS and full-length SCR1 probes were used to detect the SCR1 RNA (loading control). [a-

${ }^{32}$ P]-dCTP (Perkin Elmer, Blu513Z) and a random primed DNA labeling kit (Roche, \# 11004-760-001) were used to generate probes according to the manufacturer's protocol. Signals from northern blots were detected and analyzed by phosphorimaging using a Fujifilm bio-imaging analyzer (BAS-2500) and MultiGauge software.

\section{Calculation of readthrough and termination efficiencies}

The following formulas were used to determine the relative efficiencies of readthrough and termination:

$$
\begin{aligned}
& \text { Relative readthrough efficiency }=\frac{\frac{F L A G}{P g k 1}}{\frac{L U C m R N A}{S C R 1 R N A}} \\
& \text { Relative termination efficiency }=\frac{\frac{H A *}{P g k 1}}{\frac{L U C m R N A}{S C R 1 R N A}}
\end{aligned}
$$

In these formulas FLAG, Pgk1, and $H A^{*}$ respectively represent the amounts of full-length FLAG-tagged Luc protein, Pgk1 protein, and prematurely terminated HA-tagged Luc protein determined by western blotting, and LUC mRNA and SCR1 RNA respectively designate the levels of these two transcripts determined by northern blotting. The results shown in the figures are the average of three independent experiments +/- SEM unless otherwise indicated.

\section{ACKNOWLEDGMENTS}

This work was supported by grants to A.J. (5R01 GM27757-37 and 1R35GM122468-03) from the U.S. National Institutes of Health. We thank Robin Ganesan, Kotchaphorn Mangkalaphiban, Andrei Korostelev, Christine Carbone, and Denis Susorov for helpful discussions and insightful comments about the manuscript. 


\section{AUTHOR CONTRIBUTIONS}

C.W., B.R., F.H., and A.J. conceived and designed the experiments, C.W. and B.R. carried out the experiments, C.W. and A.J. wrote the paper with input from all authors, and A.J. obtained funding for the study.

\section{DECLARATION OF INTERESTS}

A.J. is co-founder, director, and SAB chair of PTC Therapeutics Inc. B.R. is an employee of New England Biolabs. All other authors declare no competing interests. 


\section{REFERENCES}

Alkalaeva, E.Z., Pisarev, A.V., Frolova, L.Y., Kisselev, L.L., and Pestova, T.V. (2006). In vitro reconstitution of eukaryotic translation reveals cooperativity between release factors eRF1 and eRF3. Cell 125, 1125-1136.

Amrani, N., Dong, S., He, F., Ganesan, R., Ghosh, S., Kervestin, S., Li, C., Mangus, D.A., Spatrick, P., and Jacobson, A. (2006a). Aberrant termination triggers nonsense-mediated mRNA decay. Biochem Soc Trans 34 (part 1), 39-42.

Amrani, N., Ganesan, R., Kervestin, S., Mangus, D.A., Ghosh, S., and Jacobson, A. (2004). A faux 3'-UTR promotes aberrant termination and triggers nonsense-mediated mRNA decay. Nature 432, 112-118.

Amrani, N., and Jacobson, A. (2006). All termination events are not equal: premature termination is aberrant and triggers NMD. In Nonsense-mediated mRNA decay, L.E. Maquat, ed. (Georgetown, TX: Landes Bioscience), pp. 15-25.

Amrani, N., Sachs, M.S., and Jacobson, A. (2006b). Early nonsense: mRNA decay solves a translational problem. Nat Rev Mol Cell Biol 7, 415-425.

Andoh, T., and Ozeki, H. (1968). Suppressor gene Su3+ of E. coli, a structural gene for tyrosine TRNA. Proc Natl Acad Sci USA 59, 792-799.

Anzalone, A.V., Zairis, S., Lin, A.J., Rabadan, R., and Cornish, V.W. (2019). Interrogation of Eukaryotic Stop Codon Readthrough Signals by in Vitro RNA Selection. Biochemistry 58, 1167-1178.

Bonetti, B., Fu, L., Moon, J., and Bedwell, D.M. (1995). The efficiency of translation termination is determined by a synergistic interplay between upstream and downstream sequences in Saccharomyces cerevisiae. J Mol Biol 251, 334-345.

Brenner, S., Stretton, A.O., and Kaplan, S. (1965). Genetic code: the 'nonsense' triplets for chain termination and their suppression. Nature 206, 994-998.

Brown, A., Shao, S., Murray, J., Hegde, R.S., and Ramakrishnan, V. (2015). Structural basis for stop codon recognition in eukaryotes. Nature 524, 493-496.

Bucheli, M.E., He, X., Kaplan, C.D., Moore, C.L., and Buratowski, S. (2007). Polyadenylation site choice in yeast is affected by competition between Npl3 and polyadenylation factor CFI. RNA (New York, NY) 13, 1756-1764.

Capecchi, M.R., and Gussin, G.N. (1965). Suppression in vitro: Identification of a SerinesRNA as a "Nonsense" Suppressor. Science 149, 417-422.

Carnes, J., Jacobson, M., Leinwand, L., and Yarus, M. (2003). Stop codon suppression via inhibition of eRF1 expression. RNA (New York, NY) 9, 648-653.

Chernoff, Y.O., Vincent, A., and Liebman, S.W. (1994). Mutations in eukaryotic $18 S$ ribosomal RNA affect translational fidelity and resistance to aminoglycoside antibiotics. The EMBO Journal 13, 906-913. 
Cosson, B., Berkova, N., Couturier, A., Chabelskaya, S., Philippe, M., and Zhouravleva, G. (2002a). Poly(A)-binding protein and eRF3 are associated in vivo in human and Xenopus cells. Biol Cell 94, 205-216.

Cosson, B., Couturier, A., Chabelskaya, S., Kiktev, D., Inge-Vechtomov, S., Philippe, M., and Zhouravleva, G. (2002b). Poly(A)-binding protein acts in translation termination via eukaryotic release factor 3 interaction and does not influence [PSI(+)] propagation. Mol Cell Biol 22, 3301-3315.

Cridge, A.G., Crowe-McAuliffe, C., Mathew, S.F., and Tate, W.P. (2018). Eukaryotic translational termination efficiency is influenced by the $3^{\prime}$ nucleotides within the ribosomal mRNA channel. Nucleic Acids Research 46, 1927-1944.

Dunn, J.G., Foo, C.K., Belletier, N.G., Gavis, E.R., and Weissman, J.S. (2013). Ribosome profiling reveals pervasive and regulated stop codon readthrough in Drosophila melanogaster. eLife 2, e01179.

Engelhardt, D.L., Webster, R.E., Wilhelm, R.C., and Zinder, N. (1965). In vitro studies on the mechanism of suppression of a nonsense mutation. Proc Natl Acad Sci USA 54, 17911797.

Eswarappa, S.M., Potdar, A.A., Koch, W.J., Fan, Y., Vasu, K., Lindner, D., Willard, B., Graham, L.M., DiCorleto, P.E., and Fox, P.L. (2014). Programmed translational readthrough generates antiangiogenic VEGF-Ax. Cell 157, 1605-1618.

Hagan, K.W., Ruiz-Echevarria, M.J., Quan, Y., and Peltz, S.W. (1995). Characterization of cis-acting sequences and decay intermediates involved in nonsense-mediated mRNA turnover. Mol Cell Biol 15, 809-823.

Harrell, L., Melcher, U., and Atkins, J.F. (2002). Predominance of six different hexanucleotide recoding signals 3 ' of read-through stop codons. Nucleic Acids Research 30, 2011-2017.

He, F., Brown, A.H., and Jacobson, A. (1997). Upf1p, Nmd2p, and Upf3p are interacting components of the yeast nonsense-mediated mRNA decay pathway. Molecular and Cellular Biology 17, 1580-1594.

He, F., and Jacobson, A. (1995). Identification of a novel component of the nonsensemediated mRNA decay pathway by use of an interacting protein screen. Genes \& development 9, 437-454.

He, F., and Jacobson, A. (2015). Nonsense-mediated mRNA decay: Degradation of defective transcripts is only part of the story. Ann Rev Genet 49, 339-366.

Heaphy, S.M., Mariotti, M., Gladyshev, V.N., Atkins, J.F., and Baranov, P.V. (2016). Novel Ciliate Genetic Code Variants Including the Reassignment of All Three Stop Codons to Sense Codons in Condylostoma magnum. Mol Biol Evol 33, 2885-2889.

Hennigan, A.N., and Jacobson, A. (1996). Functional mapping of the translationdependent instability element of yeast MATa1 mRNA. Mol Cell Biol 16, 3833-3843.

Hennigan, A.N., and Jacobson, A. (1997). A genetic approach to mapping coding region determinants of mRNA stability in yeast. In mRNA Formation and Function, J.D. Richter, ed. (San Diego: Academic Press), pp. 149-161. 
Herrick, D., Parker, R., and Jacobson, A. (1990). Identification and comparison of stable and unstable mRNAs in Saccharomyces cerevisiae. Molecular and cellular biology 10, 2269-2284.

Hirawat, S., Welch, E.M., Elfring, G.L., Northcutt, V.J., Paushkin, S., Hwang, S., Leonard, E.M., Almstead, N.G., Ju, W., Peltz, S.W., et al. (2007). Safety, tolerability, and pharmacokinetics of PTC124, a nonaminoglycoside nonsense mutation suppressor, following single- and multiple-dose administration to healthy male and female adult volunteers. J Clin Pharmacol 47, 430-444.

Hoshino, S., Hosoda, N., Araki, Y., Kobayashi, T., Uchida, N., Funakoshi, Y., and Katada, T. (1999). Novel function of the eukaryotic polypeptide-chain releasing factor 3 (eRF3/GSPT) in the mRNA degradation pathway. Biochemistry (Mosc) 64, 1367-1372.

Hosoda, N., Kobayashi, T., Uchida, N., Funakoshi, Y., Kikuchi, Y., Hoshino, S., and Katada, T. (2003). Translation termination factor eRF3 mediates mRNA decay through the regulation of deadenylation. J Biol Chem 278, 38287-38291.

Howard, M.T., Shirts, B.H., Petros, L.M., Flanigan, K.M., Gesteland, R.F., and Atkins, J.F. (2000). Sequence specificity of aminoglycoside-induced stop codon readthrough: potential implications for treatment of Duchenne muscular dystrophy. Ann Neurol 48, 164169.

Ivanov, A., Mikhailova, T., Eliseev, B., Yeramala, L., Sokolova, E., Susorov, D., Shuvalov, A., Schaffitzel, C., and Alkalaeva, E. (2016). PABP enhances release factor recruitment and stop codon recognition during translation termination. Nucleic Acids Res 44, 77667776.

Jerbi, S., Jolles, B., Bouceba, T., and Jean-Jean, O. (2016). Studies on human eRF3$\mathrm{PABP}$ interaction reveal the influence of eRF3a N-terminal glycin repeat on eRF3-PABP binding affinity and the lower affinity of eRF3a 12-GGC allele involved in cancer susceptibility. RNA Biol 13, 306-315.

Johansson, M.J., and Jacobson, A. (2010). Nonsense-mediated mRNA decay maintains translational fidelity by limiting magnesium uptake. Genes Dev 24, 1491-1495.

Jungreis, I., Lin, M.F., Spokony, R., Chan, C.S., Negre, N., Victorsen, A., White, K.P., and Kellis, M. (2011). Evidence of abundant stop codon readthrough in Drosophila and other metazoa. Genome Res 21, 2096-2113.

Kato, M., Yang, Y.S., Sutter, B.M., Wang, Y., McKnight, S.L., and Tu, B.P. (2019). Redox State Controls Phase Separation of the Yeast Ataxin-2 Protein via Reversible Oxidation of Its Methionine-Rich Low-Complexity Domain. Cell 177, 711-721 e718.

Kebaara, B.W., and Atkin, A.L. (2009). Long 3'-UTRs target wild-type mRNAs for nonsense-mediated mRNA decay in Saccharomyces cerevisiae. Nucleic Acids Res 37, 2771-2778.

Keeling, K.M., Xue, X., Gunn, G., and Bedwell, D.M. (2014). Therapeutics Based on Stop Codon Readthrough. Annu Rev Genomics Hum Genet 15, 8.1-8.24. 
Kessler, S.H., and Sachs, A.B. (1998). RNA recognition motif 2 of yeast Pab1p is required for its functional interaction with eukaryotic translation initiation factor 4G. Molecular and cellular biology 18, 51-57.

Klagges, B.R.E., Heimbeck, G., Godenschwege, T.A., Hofbauer, A., Pflugfelder, G.O., Reifegerste, R., Reisch, D., Schaupp, M., Buchner, S., and Buchner, E. (1996). Invertebrate Synapsins: A Single Gene Codes for Several Isoforms in $<$ strong $><$ em $>$ Drosophila</em $></$ strong $>$. The Journal of Neuroscience 16, 3154-3165.

Kononenko, A.V., Mitkevich, V.A., Atkinson, G.C., Tenson, T., Dubovaya, V.I., Frolova, L.Y., Makarov, A.A., and Hauryliuk, V. (2010). GTP-dependent structural rearrangement of the eRF1:eRF3 complex and eRF3 sequence motifs essential for PABP binding. Nucleic Acids Res 38, 548-558.

Kuroha, K., Tatematsu, T., and Inada, T. (2009). Upf1 stimulates degradation of the product derived from aberrant messenger RNA containing a specific nonsense mutation by the proteasome. EMBO Rep 10, 1265-1271.

Leeds, P., Peltz, S.W., Jacobson, A., and Culbertson, M.R. (1991). The product of the yeast UPF1 gene is required for rapid turnover of mRNAs containing a premature translational termination codon. Genes Dev 5, 2303-2314.

Liu, R., and Liebman, S.W. (1996). A translational fidelity mutation in the universally conserved sarcin/ricin domain of 25S yeast ribosomal RNA. RNA 2, 254-263.

Loenarz, C., Sekirnik, R., Thalhammer, A., Ge, W., Spivakovsky, E., Mackeen, M.M., McDonough, M.A., Cockman, M.E., Kessler, B.M., Ratcliffe, P.J., et al. (2014). Hydroxylation of the eukaryotic ribosomal decoding center affects translational accuracy. Proceedings of the National Academy of Sciences 111, 4019-4024.

Longtine, M.S., Mckenzie III, A., Demarini, D.J., Shah, N.G., Wach, A., Brachat, A., Philippsen, P., and Pringle, J.R. (1998). Additional modules for versatile and economical PCR-based gene deletion and modification in Saccharomyces cerevisiae. Yeast 14, 953961.

Loughran, G., Chou, M.Y., Ivanov, I.P., Jungreis, I., Kellis, M., Kiran, A.M., Baranov, P.V., and Atkins, J.F. (2014). Evidence of efficient stop codon readthrough in four mammalian genes. Nucleic Acids Res 42, 8928-8938.

Mangus, D.A., Amrani, N., and Jacobson, A. (1998a). Pbp1p, a factor interacting with Saccharomyces cerevisiae poly(A)-binding protein, regulates polyadenylation. Mol Cell Biol 18, 7383-7396.

Mangus, D.A., Amrani, N., and Jacobson, A. (1998b). Pbp1p, a Factor Interacting with<em $>$ Saccharomyces cerevisiae</em> Poly(A)-Binding Protein, Regulates Polyadenylation. Molecular and Cellular Biology 18, 7383-7396.

Manuvakhova, M., Keeling, K., and Bedwell, D.M. (2000). Aminoglycoside antibiotics mediate context-dependent suppression of termination codons in a mammalian translation system. RNA 6, 1044-1055. 
McCaughan, K.K., Brown, C.M., Dalphin, M.E., Berry, M.J., and Tate, W.P. (1995). Translational termination efficiency in mammals is influenced by the base following the stop codon. Proc Natl Acad Sci USA 92, 5431-5435.

Mottagui-Tabar, S., Tuite, M.F., and Isaksson, L.A. (1998). The influence of 5' codon context on translation termination in Saccharomyces cerevisiae. Eur J Biochem 257, 249254.

Muhlrad, D., and Parker, R. (1999). Aberrant mRNAs with extended 3' UTRs are substrates for rapid degradation by mRNA surveillance. RNA 5, 1299-1307.

Namy, O., Duchateau-Nguyen, G., Hatin, I., Hermann-Le Denmat, S., Termier, M., and Rousset, J.P. (2003). Identification of stop codon readthrough genes in Saccharomyces cerevisiae. Nucleic Acids Res 31, 2289-2296.

Namy, O., Duchateau-Nguyen, G., and Rousset, J.P. (2002). Translational readthrough of the PDE2 stop codon modulates cAMP levels in Saccharomyces cerevisiae. Mol Microbiol 43, 641-652.

Namy, O., Hatin, I., and Rousset, J.-P. (2001). Impact of the six nucleotides downstream of the stop codon on translation termination. EMBO reports 2, 787-793.

Peltz, S.W., Brown, A.H., and Jacobson, A. (1993). mRNA destabilization triggered by premature translational termination depends on at least three cis-acting sequence elements and one trans-acting factor. Genes Dev 7, 1737-1754.

Peltz, S.W., He, F., Welch, E., and Jacobson, A. (1994). Nonsense-mediated mRNA decay in yeast. Prog Nucleic Acid Res Mol Biol 47, 271-298.

Peltz, S.W., and Jacobson, A. (1993). mRNA Turnover in Saccharomyces cerevisiae. (NY: Academic Press).

Peltz, S.W., Morsy, M., Welch, E.M., and Jacobson, A. (2013). Ataluren as an agent for therapeutic nonsense suppression. Annu Rev Med 64, 407-425.

Robinson, D.N., and Cooley, L. (1997). Examination of the function of two kelch proteins generated by stop codon suppression. Development 124, 1405-1417.

Roque, S., Cerciat, M., Gaugue, I., Mora, L., Floch, A.G., de Zamaroczy, M., HeurgueHamard, V., and Kervestin, S. (2015). Interaction between the poly(A)-binding protein Pab1 and the eukaryotic release factor eRF3 regulates translation termination but not mRNA decay in Saccharomyces cerevisiae. RNA 21, 124-134.

Roy, B., Friesen, W.J., Tomizawa, Y., Leszyk, J.D., Zhuo, J., Johnson, B., Dakka, J., Trotta, C.R., Xue, X., Mutyam, V., et al. (2016). Ataluren stimulates ribosomal selection of near-cognate tRNAs to promote nonsense suppression. Proc Natl Acad Sci U S A 113, 12508-12513.

Roy, B., Leszyk, J.D., Mangus, D.A., and Jacobson, A. (2015a). Nonsense suppression by near-cognate tRNAs employs alternative base pairing at codon positions 1 and 3. Proc Natl Acad Sci U S A 112, 3038-3043.

Roy, B., Leszyk, J.D., Mangus, D.A., and Jacobson, A. (2015b). Nonsense suppression by near-cognate tRNAs employs alternative base pairing at codon positions 1 and 3 . 
Proceedings of the National Academy of Sciences of the United States of America 112, 3038-3043.

Sachs, A.B., Bond, M.W., and Kornberg, R.D. (1986). A single gene from yeast for both nuclear and cytoplasmic polyadenylate-binding proteins: domain structure and expression. Cell 45, 827-835.

Sachs, A.B., Davis, R.W., and Kornberg, R.D. (1987). A single domain of yeast poly(A)binding protein is necessary and sufficient for RNA binding and cell viability. Mol Cell Biol 7, 3268-3276.

Salas-Marco, J., and Bedwell, D.M. (2004). GTP hydrolysis by eRF3 facilitates stop codon decoding during eukaryotic translation termination. Mol Cell Biol 24, 7769-7778.

Schiestl, R.H., and Gietz, R.D. (1989). High efficiency transformation of intact yeast cells using single stranded nucleic acids as a carrier. Current Genetics 16, 339-346.

Schueren, F., Lingner, T., George, R., Hofhuis, J., Dickel, C., Gärtner, J., and Thoms, S. (2014). Peroxisomal lactate dehydrogenase is generated by translational readthrough in mammals. elife 3, e03640.

Serio, T.R., and Lindquist, S.L. (1999). [PSI+]: an epigenetic modulator of translation termination efficiency. Ann Rev Cell Dev Biol 15, 661-703.

Singleton, R., Liu-Yi, P., Formenti, F., Ge, W., Sekirnik, R., Fischer, R., Adam, J., Pollard, P., Wolf, A., Thalhammer, A., et al. (2014). OGFOD1 catalyzes prolyl hydroxylation of RPS23 and is involved in translation control and stress granule formation. Proceedings of the National Academy of Sciences of the United States of America 111.

Skuzeski, J.M., Nichols, L.M., Gesteland, R.F., and Atkins, J.F. (1991). The signal for a leaky UAG stop codon in several plant viruses includes the two downstream codons. Journal of Molecular Biology 218, 365-373.

Stansfield, I., Jones, K.M., Kushnirov, V.V., Dagkesamanskaya, A.R., Poznyakovski, A.I., Paushkin, S.V., Nierras, C.R., Cox, B.S., Ter-Avanesyan, M.D., and Tuite, M.F. (1995). The products of the SUP45 (eRF1) and SUP35 genes interact to mediate translation termination in Saccharomyces cerevisiae. EMBO J 14, 4365-4373.

Steneberg, P., and Samakovlis, C. (2001). A novel stop codon readthrough mechanism produces functional Headcase protein in Drosophila trachea. EMBO Rep 2, 593-597.

Stiebler, A.C., Freitag, J., Schink, K.O., Stehlik, T., Tillmann, B.A.M., Ast, J., and Bölker, M. (2014). Ribosomal readthrough at a short UGA stop codon context triggers dual localization of metabolic enzymes in Fungi and animals. PLoS Genet 10, e1004685e1004685.

Swart, E.C., Serra, V., Petroni, G., and Nowacki, M. (2016). Genetic Codes with No Dedicated Stop Codon: Context-Dependent Translation Termination. Cell 166, 691-702.

Tork, S., Hatin, I., Rousset, J.P., and Fabret, C.I. (2004). The major 5' determinant in stop codon read-through involves two adjacent adenines. Nucleic Acids Research 32, 415421. 
Uchida, N., Hoshino, S., Imataka, H., Sonenberg, N., and Katada, T. (2002). A novel role of the mammalian GSPT/eRF3 associating with poly(A)-binding protein in cap/poly(A)dependent translation. J Biol Chem 277, 50286-50292.

Velichutina, I.V., Dresios, J., Hong, J.Y., Li, C., Mankin, A., Synetos, D., and Liebman, S.W. (2000). Mutations in helix 27 of the yeast Saccharomyces cerevisiae 18S rRNA affect the function of the decoding center of the ribosome. RNA 6, 1174-1184.

Weiner, A.M., and Weber, K. (1971). Natural Read-through at the UGA Termination Signal of $Q \beta$ Coat Protein Cistron. Nature New Biology 234, 206-209.

Welch, E.M., Barton, E.R., Zhuo, J., Tomizawa, Y., Friesen, W.J., Trifillis, P., Paushkin, S., Patel, M., Trotta, C.R., Hwang, S., et al. (2007). PTC124 targets genetic disorders caused by nonsense mutations. Nature 447, 87-91.

Yang, Y.S., Kato, M., Wu, X., Litsios, A., Sutter, B.M., Wang, Y., Hsu, C.H., Wood, N.E., Lemoff, A., Mirzaei, H., et al. (2019). Yeast Ataxin-2 Forms an Intracellular Condensate Required for the Inhibition of TORC1 Signaling during Respiratory Growth. Cell 177, 697710 e617.

Zahonova, K., Kostygov, A.Y., Sevcikova, T., Yurchenko, V., and Elias, M. (2016). An Unprecedented Non-canonical Nuclear Genetic Code with All Three Termination Codons Reassigned as Sense Codons. Curr Biol 26, 2364-2369.

Zhouravleva, G., Frolova, L., Le Goff, X., Le Guellec, R., Inge-Vechtomov, S., Kisselev, L., and Philippe, M. (1995). Termination of translation in eukaryotes is governed by two interacting polypeptide chain release factors, eRF1 and eRF3. EMBO J 14, 4065-4072. 
Figure 1. PTC readthrough efficiency decreases across the LUC ORF in upf1 $\Delta$ cells A. PTC readthrough reporters. Schematic representation of the respective positions of PTCs and the normal termination codon (NTC) within individual HA-LUC-SF constructs used to analyze readthrough and termination efficiency in yeast. The UGACAA sequence context was used in all PTC alleles, each of which was transformed into WT or upf1 $\Delta$ cells to assess readthrough and termination efficiencies. HA, S, F= HA, Strepll, and FLAG epitope tags, respectively.

\section{B. Western analyses of full-length readthrough proteins and prematurely} terminated polypeptides expressed from LUC PTC alleles. Each of the six LUC PTC alleles, a vector control, and a wild-type LUC allele was expressed in separate cultures of WT or upf1 1 yeast cells that were subsequently harvested, lysed, and analyzed by western blotting using anti-FLAG antibodies to detect full-length readthrough products, anti-HA antibodies to detect premature termination products, and anti-Pgk1 antibodies to detect the Pgk1 control protein. The arrow in the upper panel indicates the full-length readthrough protein and the asterisks in the middle panel indicate premature termination products. Figure S1D shows the complete blot used for the top panel of Figure 1B.

C. Northern analyses of LUC mRNA levels in cells expressing different PTC alleles. Northern blotting and phosphorimaging were utilized to measure the level of LUC mRNA and SCR1 RNA in each sample.

D, E. Relative readthrough efficiency at each of the six LUC PTCs. Densitometry was utilized to quantitate the western blots in part B and the northern blots in part $C$. Relative readthrough efficiency of each sample was calculated as the ratio of full-length Luc protein level (anti-FLAG) normalized to Pgk1 level divided by LUC mRNA level normalized to the level of SCR1 RNA. The efficiency of LUC PTC20 expression in WT cells (in part D) or upf1 $\Delta$ cells (in part E) was set as 1 . Three independent experiments were performed and the results shown are the average of all three +/- SEM. 1\% Luc-wt and 2\% Luc-wt: aliquots of extracts from cells expressing a wild-type LUC allele that were $1 / 100^{\text {th }}$ and $1 / 50^{\text {th }}$ the volume of samples from cells expressing PTC alleles.

Figure S1. MG132 treatment has no significant effect on the expression of readthrough and premature termination products generated from LUC PTC alleles 
in upf1 $\Delta$ cells

\section{A. Western analyses of polypeptides expressed from different LUC PTC alleles in} mock- or MG132-treated upf1A cells. Each of the cultures was processed as in Figure $1 \mathrm{~B}$, except that the growth media were supplemented with either $0.05 \%$ DMSO or $0.1 \mathrm{mM}$ MG132.

B. Relative levels of full-length readthrough products expressed from each of the six LUC PTC alleles in mock- or MG132-treated upf1 $\Delta$ cells. Densitometry was utilized to quantitate the western blots in part $A$ and relative recoveries were calculated by determining each sample's full-length Luc protein level (anti-FLAG band) normalized to its Pgk1 level. The LUC PTC20 sample was set as 1 in each group.

C. Western analysis of the HA-Luc19 peptide. Synthetic HA-Luc19 peptide was mixed with one of two aliquots of LUC PTC20 cell lysate and both samples were processed for western blotting, with detection by anti-HA antibodies. Left lane: LUC PTC20 cell lysate containing HA-Luc19 peptide; right lane: LUC PTC20 cell lysate only.

D. Complete western blot used to depict full-length readthrough protein in the top panel of Figure 1B. The same western blot from which a segment was used to illustrate the extent of readthrough protein accumulation in Figure 1B is shown in its entirety.

Figure 2. Alterations of the 3'-UTR associated with the LUC ORF affect readthrough efficiency

A. Schematic representation of 3'-UTR deletion reporters. LUC PTC520 alleles harboring different deletions (indicated by the dashed bars) in the TPI1 3' region were constructed and each of the these alleles was separately transformed into upf1 $\Delta$ cells to assess expression of both mRNA and protein. $p T P I 1=T P I 1$ promoter. $S F=S t r e p / I-F L A G$ tag. FL=Full-length TPI1 3'-region.

B. Western and northern analyses of 3'-UTR deletion reporters. Yeast upf1 $\Delta$ cells harboring the original LUC PTC520 allele, each of the 3'-UTR deletion alleles, and an empty vector were cultured separately and samples were processed as in Figure 1. In the upper panel (western blot), anti-FLAG antibodies detected full-length readthrough products and anti-Pgk1 antibodies detected the control protein in each sample. In the lower panel, northern blotting was used to assess the levels of LUC mRNA and SCR1 
RNA in each sample.

C. Relative readthrough efficiency of 3'-UTR deletion reporters. Relative readthrough efficiency was calculated as in Figure 1D, using the data obtained from western and northern blotting experiments like those in Figure $2 \mathrm{~B}$. The results shown are the average of three independent experiments $+/$ - SEM.

Figure 3. 3'-UTR deletions only affect LUC PTC readthrough efficiency when mRNA length is altered

A. Schematic representation of LUC PTC520 reporters with different deletions in the TPI1 3'-UTR. A set of LUC PTC520 alleles harboring different deletions in the TPI1 3'-UTR (indicated by dashed bars) was constructed. As in Figure 2, each of the constructs was transformed into upf1 $\triangle$ cells for subsequent determination of LUC mRNA and protein levels. $p T P I 1=T P I 1$ promoter. $S F=S t r e p / I-F L A G$ tag. $F L=F u l l-l e n g t h ~ T P I 13$ '-region.

B. Analyses of mRNA and readthrough products generated from LUC PTC520 reporters with different 3'-UTR deletions. In the upper panel, anti-FLAG antibodies were used to detect full-length readthrough protein generated from each of the alleles, and anti-Pgk1 antibodies were used to detect the control Pgk1 protein. In the lower panel, northern blotting was used to assess the levels of LUC mRNA and SCR1 RNA in each sample.

C. Relative readthrough efficiency of LUC PTC520 reporters with different 3'-UTR deletions. Relative readthrough efficiencies were calculated as in Figure 1D. The results shown are the average of three independent experiments +/- SEM.

Figure 4. The increased readthrough efficiency of mRNAs with extended 3'-UTRs is reversed when the 3'-UTR is shortened

A. LUC PTC520 alleles with insertions of the GAL7 cleavage/polyadenylation signal. The GAL7 cleavage/polyadenylation signal (shown in pink) was inserted between nts 130 and 131 of short (100nt-199nt) and long (100nt-298nt) derivatives of the TPI1 3' region to generate the $S$ and $L$ alleles. These LUC PTC520 alleles were transformed into upf1 $\triangle$ cells to assess mRNA and protein expression. $p T P I 1=T P I 1$ promoter. $S F=S t r e p / I-F L A G$ tag. FL=Full-length TPI1 3'-region. S, L= short or long derivatives of the TPI1 3'-UTR. 
B. mRNAs and readthrough products generated from the LUC PTC520 S and L alleles. As in Figure 1B, the levels of full-length readthrough protein and Pgk1 control protein derived from cells expressing each allele were analyzed by western blotting. In the lower panel, northern blotting was used to assess each sample's levels of LUC mRNA and SCR1 RNA.

C. Relative readthrough efficiencies of the LUC PTC520 S and L alleles. Relative readthrough efficiencies were calculated as in Figure 1D. The results shown are the average of three independent experiments +/- SEM. In both B and C, results from expression of the LUC PTC520 FL and $\Delta 1-99$ alleles were included for comparison.

Figure 5. The efficiency of readthrough of LUC PTC520 mRNA varies directly with the length of its associated 3'-UTR

A. Schematic representation of LUC PTC520 alleles with defined 3'-UTR lengths. The GAL7 cleavage/polyadenylation signal (pink rectangles) was inserted at different locations downstream of the LUC PTC520 ORF ( $\triangle F L$ allele in Figure 2) to generate a set of LUC PTC520 alleles. The individual alleles were transformed into upf1 cells for assessment of LUC mRNA and protein expression. mRNAs generated from this set of alleles have 3'-UTR lengths ranging from 60 to 600 nt. pTPI1=TPI1 promoter. SF=Strep/IFLAG tag. FL=Full-length TPI1 3'-region.

B. Analyses of the mRNAs and readthrough products generated by LUC PTC520 alleles with defined 3'-UTR lengths. LUC PTC520 alleles harboring 3'-UTRs of 60bp, 120bp, 200bp, 300bp, 400bp, 500bp, or 600bp were expressed in upf1 $\Delta$ cells and lysates of the respective cells were analyzed by western blotting and northern blotting as in Figure $1 \mathrm{~B}$.

C. Relative readthrough efficiencies of LUC PTC520 alleles with 3'-UTRs of defined lengths. Relative readthrough efficiencies were calculated as in Figure 1D. The results shown are the average of four independent experiments +/- SEM.

Figure 6. Deletion of PAB1 enhances translational readthrough and disrupts PTC position effects

A, B. Western and northern analyses of LUC-PTC reporter expression in upf1D, 
pab1 1 pbp1 $\Delta$ upf1 $\Delta$, and pbp1 $\Delta$ upf1 $\Delta$ cells. Each of the six LUC PTC alleles, an empty vector control, and a wild-type LUC allele was expressed in separate cultures of upf1 $\Delta$, pab1 $\Delta$ pbp1 $\Delta$ upf1 $\Delta$, and pbp1 $\Delta$ upf1 $\Delta$ cells that were subsequently harvested, lysed, and analyzed by western and northern blotting as in Figure 1B.

C. Relative readthrough efficiencies of different LUC PTC reporters in cells with and without Pab1. The relative readthrough efficiencies of each of the LUC PTC alleles in upf1 $\Delta$, pab1 $\Delta$ pbp1 $\Delta$ upf1 $\Delta$, and pbp1 $\Delta$ upf1 $\Delta$ cells were calculated as in Figure $1 D$. The results shown are the average of three independent experiments +/- SEM. 10\% Luc: aliquot of extract from cells expressing a wild-type LUC allele that was $1 / 10^{\text {th }}$ the total proteins of samples from cells expressing PTC alleles.

Figure 7. The Pab1 C-terminal domain is required for maintenance of PTC position effects

A, B. Western and northern analyses of LUC PTC reporters in upf1 $\triangle$ and pab1 $\Delta C$ upf1 yeast cells. Each of the six LUC PTC alleles, a vector control, and a wild-type LUC allele was expressed in separate cultures of upf1 $\Delta$ or pab1 $\Delta C$ upf1 $\Delta$ cells that were subsequently harvested, lysed, and analyzed by western and northern blotting as in Figure 1B.

C. Relative readthrough efficiencies of $L U C$ PTC reporters in upf1 $\Delta$ and pab1 $\Delta C$ upf1 $\Delta$ cells. Relative readthrough efficiencies were calculated as in Figure 1D and the results shown are the average of three independent experiments +/- SEM.

Figure S2. Relative termination efficiencies of the different LUC PTC alleles A. Relative termination efficiencies of LUC PTCs in upf1 Densitometry and phosphorimaging were respectively utilized to quantitate the western blots of Figure 6A and the northern blots of Figure 6B. Relative termination efficiencies were calculated as the level of prematurely terminated Luc protein level (anti-HA) normalized to the level of Pgk1 divided by the LUC mRNA level normalized to the SCR1 level. The efficiency of termination for the LUC PTC520 allele in upf1 $\Delta$ cells was set as 1. B. Relative termination efficiencies of LUC PTCs in upf1 $\Delta$ or pab1 $\Delta C$ upf1 1 cells. The western and northern blots of Figure 7A and B were used to calculate relative 
bioRxiv preprint doi: https://doi.org/10.1101/793158; this version posted October 6,2019 . The copyright holder for this preprint (which was not certified by peer review) is the author/funder. All rights reserved. No reuse allowed without permission.

termination efficiencies as in part A. Three independent experiments were performed and the results shown are the average of all three +/- SEM. 


\section{KEY RESOURCES TABLE}

\begin{tabular}{|c|c|c|}
\hline REAGENT or RESOURCE & SOURCE & IDENTIFIER \\
\hline \multicolumn{3}{|l|}{ Antibodies } \\
\hline Rabbit polyclonal anti-FLAG & Sigma-Aldrich & Cat\#F7425 \\
\hline Mouse monoclonal anti-OctA-Probe (F-tag-01) & SANTA CRUZ & Cat\#sc-51590 \\
\hline Mouse monoclonal anti-Pgk1 (22C5D8) & Thermo Fisher & Cat\#459250 \\
\hline Donkey polyclonal anti-Mouse Secondary & Thermo Fisher & Cat\#A24506 \\
\hline Donkey anti-Rabbit Secondary & Sigma-Aldrich & Cat\#GENA934 \\
\hline Mouse monoclonal anti-HA & Sigma-Aldrich & Cat\#H3663 \\
\hline \multicolumn{3}{|l|}{ Chemicals, Peptides, and Recombinant Proteins } \\
\hline Protease inhibitor tablets, EDTA-free & Thermo Fisher & Cat\#A32965 \\
\hline $\mathrm{dCTP},\left[\alpha^{-32} \mathrm{P}\right]-6000 \mathrm{Ci} / \mathrm{mmol}$ & Perkin Elmer & Cat\#BLU513Z \\
\hline MG-132 & Sigma-Aldrich & Cat\#474790 \\
\hline $\begin{array}{l}\text { Synthetic HA-Luc19: } \\
\text { MGYPYDVPDYAGYPYDVPDYAGSYPYDVPDYA } \\
\text { MEDAKNIKKGPAPFYPLED }\end{array}$ & GenScript & This paper \\
\hline \multicolumn{3}{|l|}{ Critical Commercial Assays } \\
\hline Random Primed DNA Labeling Kit & Sigma-Aldrich & Cat\#11004760001 \\
\hline \multicolumn{3}{|l|}{ Experimental Models: Organisms/Strains } \\
\hline $\begin{array}{l}\text { S. cerevisiae: upf1 (HFY871): MATa ade2-1 his3- } \\
\text { 11,15 leu2-3,112 trp1-1 ura3-1 can1-100 upf1::HIS3 }\end{array}$ & Jacobson lab & He et al., 1997 \\
\hline $\begin{array}{l}\text { S. cerevisiae: WT (HFY114): MATa ade2-1 his3-11,15 } \\
\text { leu2-3,112 trp1-1 ura3-1 can1-100 }\end{array}$ & Jacobson lab & He et al., 1997 \\
\hline $\begin{array}{l}\text { S. cerevisiae: pab1 } 1 \text { pbp1 } 1 \text { upf1 } 1 \text { : MATa ade2-1 his3- } \\
\text { 11,15 leu2-3,112 trp1-1 ura3-1 can1-100 pab1::HIS3 } \\
\text { pbp1::LEU2 upf1::KanMX6 }\end{array}$ & Jacobson lab & This paper \\
\hline $\begin{array}{l}\text { S. cerevisiae: pab1 } \triangle \text { C upf1 }: \text { : MATa ade2-1 his3-11,15 } \\
\text { leu2-3,112 trp1-1 ura3-1 can1-100 pab1 } \triangle C:: H I S 3 \\
\text { upf1::KanMX6 }\end{array}$ & Jacobson lab & This paper \\
\hline $\begin{array}{l}\text { S. cerevisiae: pbp1A upf1A: MATa ade2-1 his3-11,15 } \\
\text { leu2-3,112 trp1-1 ura3-1 can1-100 pbp1::LEU2 } \\
\text { upf1::KanMX6 }\end{array}$ & Jacobson lab & This paper \\
\hline \multicolumn{3}{|l|}{ Software and Algorithms } \\
\hline MultiGauge software & Fujifilm & Science lab 2005 \\
\hline
\end{tabular}




\section{Supplementary Table 1. Plasmids used in this study}

\begin{tabular}{|c|c|}
\hline Name & Description \\
\hline pRS315 & Yeast centromere-based vector with $L E U 2$ selection marker \\
\hline pRS315-LUC & $\begin{array}{l}\text { Contains TPI1 promoter, N-terminal 3XHA tag, firefly luciferase gene, C- } \\
\text { terminal Strepll-FLAG (SF) tag, and a 298-bp TPI1 3'-UTR fragment }\end{array}$ \\
\hline pRS315-LUC-PTC20 & $\begin{array}{l}\text { Same as pRS315-LUC but contains TGA CAA at LUC codon position } 20 \\
\text { and } 21 .\end{array}$ \\
\hline pRS315-LUC-PTC41 & $\begin{array}{l}\text { Same as pRS315-LUC but contains TGA CAA at LUC codon position } 41 \\
\text { and } 42 .\end{array}$ \\
\hline pRS315-LUC-PTC160 & $\begin{array}{l}\text { Same as pRS315-LUC but contains TGA CAA at LUC codon position } 160 \\
\text { and } 161 .\end{array}$ \\
\hline pRS315-LUC-PTC386 & $\begin{array}{l}\text { Same as pRS315-LUC but contains TGA CAA at LUC codon position } 386 \\
\text { and } 387 .\end{array}$ \\
\hline pRS315-LUC-PTC460 & $\begin{array}{l}\text { Same as pRS315-LUC but contains TGA CAA at } L U C \text { codon position } 460 \\
\text { and } 461 .\end{array}$ \\
\hline pRS315-LUC-PTC520 & $\begin{array}{l}\text { Same as pRS315-LUC but contains TGA CAA at LUC codon position } 520 \\
\text { and } 521 .\end{array}$ \\
\hline pRS316 & Yeast centromere-based vector with URA3 selection marker \\
\hline pRS316-LUC & $\begin{array}{l}\text { Contains TPI1 promoter, N-terminal 3XHA tag, firefly luciferase gene, C- } \\
\text { terminal Strepll-FLAG (SF) tag, and a 298-bp TPI1 3'-UTR fragment }\end{array}$ \\
\hline pRS316-LUC-PTC20 & $\begin{array}{l}\text { Same as pRS316-LUC but contains TGA CAA at LUC codon position } 20 \\
\text { and } 21, \text { C-terminal Strepll-FLAG (SF) tag, TPI1 3'-UTR. }\end{array}$ \\
\hline pRS316-LUC-PTC41 & $\begin{array}{l}\text { Same as pRS316-LUC but contains TGA CAA at LUC codon position } 41 \\
\text { and } 42 .\end{array}$ \\
\hline pRS316-LUC-PTC160 & $\begin{array}{l}\text { Same as pRS316-LUC but contains TGA CAA at LUC codon position } 160 \\
\text { and } 161 .\end{array}$ \\
\hline pRS316-LUC-PTC386 & $\begin{array}{l}\text { Same as pRS316-LUC but contains TGA CAA at LUC codon position } 386 \\
\text { and } 387 .\end{array}$ \\
\hline pRS316-LUC-PTC460 & $\begin{array}{l}\text { Same as pRS316-LUC but contains TGA CAA at LUC codon position } 460 \\
\text { and } 461 .\end{array}$ \\
\hline pRS316-LUC-PTC520 & $\begin{array}{l}\text { Same as pRS316-LUC but contains TGA CAA at LUC codon position } 520 \\
\text { and } 521 .\end{array}$ \\
\hline $\begin{array}{l}\text { pRS315-LUC-PTC520- } \\
\Delta 1-99\end{array}$ & $\begin{array}{l}\text { Same as pRS315-LUC-PTC520 but contains a 99-bp deletion from position } \\
1 \text { to } 99 \text { in the TPI1 3'-UTR fragment. }\end{array}$ \\
\hline $\begin{array}{l}\text { pRS315-LUC-PTC520- } \\
\Delta 1-198\end{array}$ & $\begin{array}{l}\text { Same as pRS315-LUC-PTC520 but contains a 198-bp deletion from } \\
\text { position } 1 \text { to } 198 \text { in the TPI1 3'-UTR fragment }\end{array}$ \\
\hline $\begin{array}{l}\text { pRS315-LUC-PTC520- } \\
\Delta 101-298\end{array}$ & $\begin{array}{l}\text { Same as pRS315-LUC-PTC520 but contains a 198-bp deletion from } \\
\text { position } 101 \text { to } 298 \text { in the TPI1 3'-UTR fragment. }\end{array}$ \\
\hline $\begin{array}{l}\text { pRS315-LUC-PTC520- } \\
4201-298\end{array}$ & $\begin{array}{l}\text { Same as pRS315-LUC-PTC520 but contains a 98-bp deletion from position } \\
201 \text { to } 298 \text { in the TPI1 3'-UTR fragment. }\end{array}$ \\
\hline $\begin{array}{l}\text { pRS315-LUC-PTC520- } \\
\Delta 1-24\end{array}$ & $\begin{array}{l}\text { Same as pRS315-LUC-PTC520 but contains a 24-bp deletion from position } \\
1 \text { to } 24 \text { in the TPI1 3'-UTR fragment. }\end{array}$ \\
\hline $\begin{array}{l}\text { pRS315-LUC-PTC520- } \\
\Delta 25-50\end{array}$ & $\begin{array}{l}\text { Same as pRS315-LUC-PTC520 but contains a 25-bp deletion from position } \\
25 \text { to } 50 \text { in the TPI1 3'-UTR fragment. }\end{array}$ \\
\hline $\begin{array}{l}\text { pRS315-LUC-PTC520- } \\
\Delta 1-50\end{array}$ & $\begin{array}{l}\text { Same as pRS315-LUC-PTC520 but contains a 50-bp deletion from position } \\
1 \text { to } 50 \text { in the TPI1 3'-UTR fragment. }\end{array}$ \\
\hline $\begin{array}{l}\text { pRS315-LUC-PTC520- } \\
\Delta F L\end{array}$ & $\begin{array}{l}\text { Same as pRS315-LUC-PTC520 but lacks the 298-bp TPI1 3'-UTR } \\
\text { fragment. }\end{array}$ \\
\hline
\end{tabular}




\begin{tabular}{|c|c|}
\hline $\begin{array}{l}\text { pRS315-LUC-PTC520- } \\
3 U 60\end{array}$ & $\begin{array}{l}\text { Same as pRS315-LUC-PTC520- } \triangle F L \text { but contains a } 60 \text {-bp insertion of the } \\
\text { GAL7 poly }(A) \text { adenylation signal immediately downstream the } L U C \text { stop } \\
\text { codon }\end{array}$ \\
\hline $\begin{array}{l}\text { pRS315-LUC-PTC520- } \\
3 U 120\end{array}$ & $\begin{array}{l}\text { Same as pRS315-LUC-PTC520- } \triangle F L \text { but contains a } 60 \text {-bp insertion of the } \\
\text { GAL7 poly(A) adenylation signal } 60 \text { nts downstream the } L U C \text { stop codon in } \\
\text { the vector sequence. }\end{array}$ \\
\hline $\begin{array}{l}\text { pRS315-LUC-PTC520- } \\
3 U 200\end{array}$ & $\begin{array}{l}\text { Same as pRS315-LUC-PTC520- } \triangle F L \text { but contains a } 60-\text { bp insertion of the } \\
\text { GAL7 poly }(A) \text { adenylation signal } 140 \mathrm{nts} \text { downstream the } L U C \text { stop codon } \\
\text { in the vector sequence. }\end{array}$ \\
\hline $\begin{array}{l}\text { pRS315-LUC-PTC520- } \\
3 U 300\end{array}$ & $\begin{array}{l}\text { Same as pRS315-LUC-PTC520- } \triangle F L \text { but contains a } 60-\mathrm{bp} \text { insertion of the } \\
\text { GAL7 poly }(\mathrm{A}) \text { adenylation signal d } 240 \mathrm{nts} \text { downstream the } L U C \text { stop codon } \\
\text { in the vector sequence. }\end{array}$ \\
\hline $\begin{array}{l}\text { pRS315-LUC-PTC520- } \\
3 U 400\end{array}$ & $\begin{array}{l}\text { Same as pRS315-LUC-PTC520- } \triangle F L \text { but contains a } 60 \text {-bp insertion of the } \\
\text { GAL7 poly(A) adenylation signal } 340 \text { nts downstream the } L U C \text { stop codon } \\
\text { in the vector sequence. }\end{array}$ \\
\hline $\begin{array}{l}\text { pRS315-LUC-PTC520- } \\
3 U 500\end{array}$ & $\begin{array}{l}\text { Same as pRS315-LUC-PTC520- } \triangle F L \text { but contains a } 60 \text {-bp insertion of the } \\
\text { GAL7 poly(A) adenylation signal } 440 \text { nts downstream the } L U C \text { stop codon } \\
\text { in the vector sequence. }\end{array}$ \\
\hline $\begin{array}{l}\text { pRS315-LUC-PTC520- } \\
3 U 600\end{array}$ & $\begin{array}{l}\text { Same as pRS315-LUC-PTC520- }-A F L \text { but contains a } 60 \text {-bp insertion of the } \\
\text { GAL7 poly(A) adenylation signal } 540 \text { nts downstream the } L U C \text { stop codon } \\
\text { in the vector sequence. }\end{array}$ \\
\hline pRS315-LUC-PTC520-S & $\begin{array}{l}\text { Contains TPI1 promoter, N-terminal 3XHA tag, firefly luciferase gene with } \\
\text { TGA CAA at LUC codon position } 520 \text { and 521, C-terminal Strepll-FLAG } \\
\text { (SF) tag, and a TPI1 3'-UTR fragment from position } 100 \text { to199 with the } \\
\text { GAL7 poly(A) adenylation signal inserted at position } 130 \text {. }\end{array}$ \\
\hline pRS315-LUC-PTC520-L & $\begin{array}{l}\text { Contains TPI1 promoter, N-terminal 3XHA tag, firefly luciferase gene with } \\
\text { TGA CAA at LUC codon position } 520 \text { and } 521 \text {, C-terminal Strepll-FLAG } \\
\text { (SF) tag, and a TPI1 3'-UTR from position } 100 \text { to } 298 \text { with the GAL7 poly(A) } \\
\text { signal inserted position } 130 \text {. }\end{array}$ \\
\hline
\end{tabular}

Supplementary Table 2. Oligonucleotides used in this study

\begin{tabular}{|l|l|}
\hline Name & Sequence \\
\hline upf1-KanMX6-F & $\begin{array}{l}\text { AATATACTTTTTATATTACATCAATCATTGTCATTATCAACGGATCCCCGGGTT } \\
\text { AATTAA }\end{array}$ \\
\hline upf1-KanMX6-R & $\begin{array}{l}\text { CACGGTTGAGCCGTTTTGTATCACAAGCCAAGTTTAACATGAATTCGAGCTC } \\
\text { GTTTAAAC }\end{array}$ \\
\hline upf1-SF & GGCTAGGATATCAAGTCCATGCCCC \\
\hline upf1-SR & GAGGCATCGTTTTAACGCACAC \\
\hline TPI13U-F(Xbal) & GCTCTAGATTAATATAATTATATAAAAATATTATCTTCTTTTCTTTATATCTAGT \\
\hline TPI13U-R(Notl) & ATCGGCGGCCGCTGAGTAACCCATATAGAGATCGTACACATTTTACAAGG \\
\hline $\begin{array}{l}\text { TPI1-promoter-F } \\
\text { (Pstl) }\end{array}$ & AACTGCAGGAGTTATAATAATCCTACGTTAGTGTGAGCGGG \\
\hline LUC-PTC20-F & CATTCTACCCACTCGAAGACTGACAAGCCGGCGAGCAGCTGCAC \\
\hline LUC-PTC20-R & GTGCAGCTGCTCGCCGGCTTGTCAGTCTTCGAGTGGGTAGAATG \\
\hline
\end{tabular}




\begin{tabular}{|c|c|}
\hline LUC-PTC41-F & CGCCCTGGTGCCCGGCACCATCTGACAAACCGACGCACATATCGAGGTGG \\
\hline LUC-PTC41-R & CCACCTCGATATGTGCGTCGGTTTGTCAGATGGTGCCGGGCACCAGGGCG \\
\hline LUC-PTC160-F & GGATAGCAAGACCGACTACCAGTGACAACAAAGCATGTACACCTTCGTGAC \\
\hline LUC-PTC160-R & GTCACGAAGGTGTACATGCTTTGTTGTCACTGGTAGTCGGTCTTGCTATCC \\
\hline LUC-PTC386-F & $\begin{array}{l}\text { CCGGTAAGACACTGGGTGTGAACTGACAAGGCGAGCTGTGCGTCCGTGGC } \\
\text { C }\end{array}$ \\
\hline LUC-PTC386-R & GGCCACGGACGCACAGCTCGCCTTGTCAGTTCACACCCAGTGTCTTACCGG \\
\hline LUC-PTC460-F & $\begin{array}{l}\text { GCCGAACTGGAGAGCATCCTGCTGTGACAACCCAACATCTTCGACGCCGGG } \\
\text { G }\end{array}$ \\
\hline LUC-PTC460-R & $\begin{array}{l}\text { CCCCGGCGTCGAAGATGTTGGGTTGTCACAGCAGGATGCTCTCCAGTTCGG } \\
\text { C }\end{array}$ \\
\hline LUC-PTC520-F & $\begin{array}{l}\text { GCTGCGCGGTGGTGTTGTGTTCGTGTGACAAGTGCCTAAAGGACTGACCGG } \\
\text { C }\end{array}$ \\
\hline LUC-PTC520-R & $\begin{array}{l}\text { GCCGGTCAGTCCTTTAGGCACTTGTCACACGAACACAACACCACCGCGCAG } \\
\text { C }\end{array}$ \\
\hline $\begin{array}{l}\text { TPI3U-100- } \\
\text { F(Xbal) }\end{array}$ & CCGCTCTAGATTCATTCTGAGCCACTTAAATTTCG \\
\hline $\begin{array}{l}\text { TPI3U-200- } \\
\text { F(Xbal) }\end{array}$ & CCGCTCTAGAGAAAAGCATTTAACAATTGAACACC \\
\hline $\begin{array}{l}\text { TPI3U-200- } \\
\text { R(Notl) }\end{array}$ & ATCGGCGGCCGCCTTCTTTTTATTAGAAAAAGCGCCTTG \\
\hline $\begin{array}{l}\text { TPI3U-100- } \\
\text { R(Notl) }\end{array}$ & ATCGGCGGCCGCAAAAGAAACAATATAAAAAAGCTTTCCG \\
\hline TPI3U-25-F(Xbal) & CCGCTCTAGATCTTCTTTTCTTTATATCTAGTG \\
\hline TPI3U-50-F(Xbal) & CCGCTCTAGAATGTAAAATAAATTGATGACTACGG \\
\hline $\begin{array}{l}\text { TPI3U-2550- } \\
\text { F(Xbal) }\end{array}$ & $\begin{array}{l}\text { CCGCTCTAGATTAATATAATTATATAAAAATATTATATGTAAAATAAATTGATG } \\
\text { AC }\end{array}$ \\
\hline $100 \mathrm{~S}-\mathrm{F}$ & $\begin{array}{l}\text { CTAGATTCATTCTGAGCCACTTAAATTTCGTGAATGAACGGAGTGACAATATA } \\
\text { TATATATATATATTTAATAATGACATCATTATCTGTAAATCTGAGTTCTTGTAA } \\
\text { GGGACGGTAGATTTACAAGTGATACAACAAAAAGCAAGGCGCTTTTTCTAAT } \\
\text { AAAAAGAAGC }\end{array}$ \\
\hline 100S-R & $\begin{array}{l}\text { GGCCGCTTCTTTTTATTAGAAAAAGCGCCTTGCTTTTTGTTGTATCACTTGTA } \\
\text { AATCTACCGTCCCTTACAAGAACTCAGATTTACAGATAATGATGTCATTATTA } \\
\text { AATATATATATATATATATTGTCACTCCGTTCATTCACGAAATTTAAGTGGCTC } \\
\text { AGAATGAAT }\end{array}$ \\
\hline 200L-F(Xbal) & $\begin{array}{l}\text { GCTCTAGATTCATTCTGAGCCACTTAAATTTCGTGAATGAACGGAGTGACAAT } \\
\text { ATATATATATATATATTTAATAATGACATCATTATCTGTAAATCTGAGTTCTTGT } \\
\text { AAGGGACGGTAG }\end{array}$ \\
\hline 3U120-R & $\begin{array}{l}\text { TCAGATTTACAGATAATGATGTCATTATTAAATATATATATATATATATTGTCAC } \\
\text { TCCGTTCAGTGAATTGTAATACGACTC }\end{array}$ \\
\hline 3U120-F & $\begin{array}{l}\text { GAACGGAGTGACAATATATATATATATATATTTAATAATGACATCATTATCTGT } \\
\text { AAATCTGAGGCCGTCGTTTTACAACGTCG }\end{array}$ \\
\hline 3U200-R & $\begin{array}{l}\text { TCAGATTTACAGATAATGATGTCATTATTAAATATATATATATATATATTGTCAC } \\
\text { TCCGTTCCGAAGGGGGGATGTGCTGC }\end{array}$ \\
\hline $3 \mathrm{U} 200-\mathrm{F}$ & $\begin{array}{l}\text { GAACGGAGTGACAATATATATATATATATATTTAATAATGACATCATTATCTGT } \\
\text { AAATCTGACCAGCTGGCGTAATAGCGAAG }\end{array}$ \\
\hline $3 U 300-R$ & $\begin{array}{l}\text { TCAGATTTACAGATAATGATGTCATTATTAAATATATATATATATATATTGTCAC } \\
\text { TCCGTTCAATGCGCCGCTACAGGGCGC }\end{array}$ \\
\hline
\end{tabular}




\begin{tabular}{|c|c|}
\hline 3U300-F & $\begin{array}{l}\text { GAACGGAGTGACAATATATATATATATATATTTAATAATGACATCATTATCTGT } \\
\text { AAATCTGAAAGCGCGGCGGGTGTGGTGG }\end{array}$ \\
\hline $3 U 400-R$ & $\begin{array}{l}\text { TCAGATTTACAGATAATGATGTCATTATTAAATATATATATATATATATTGTCAC } \\
\text { TCCGTTCCGTGGCGAGAAAGGAAGGG }\end{array}$ \\
\hline $3 U 400-F$ & $\begin{array}{l}\text { GAACGGAGTGACAATATATATATATATATATTTAATAATGACATCATTATCTGT } \\
\text { AAATCTGATTCGCCGGCTTTCCCCGTC }\end{array}$ \\
\hline 3U500-R & $\begin{array}{l}\text { TCAGATTTACAGATAATGATGTCATTATTAAATATATATATATATATATTGTCAC } \\
\text { TCCGTTCCACCCTAATCAAGTTTTTTGGGG }\end{array}$ \\
\hline $3 \mathrm{U} 500-\mathrm{F}$ & $\begin{array}{l}\text { GAACGGAGTGACAATATATATATATATATATTTAATAATGACATCATTATCTGT } \\
\text { AAATCTGAATGGTTCACGTAGTGGGCC }\end{array}$ \\
\hline $3 U 600-R$ & $\begin{array}{l}\text { TCAGATTTACAGATAATGATGTCATTATTAAATATATATATATATATATTGTCAC } \\
\text { TCCGTTCGTTCCAGTTTGGAACAAGAG }\end{array}$ \\
\hline $3 U 600-F$ & $\begin{array}{l}\text { GAACGGAGTGACAATATATATATATATATATTTAATAATGACATCATTATCTGT } \\
\text { AAATCTGAAACACTCAACCCTATCTCGG }\end{array}$ \\
\hline RS315-F-Sall & CGAGGTCGACGGTATCGATAAG \\
\hline RS315-R-Kasl & CTTGAATCAGGCGCCTTAGACC \\
\hline GAL7-3U-F & $\begin{array}{l}\text { CTAGAGAACGGAGTGACAATATATATATATATATATTTAATAATGACATCATTA } \\
\text { TCTGTAAATCTGAGC }\end{array}$ \\
\hline GAL7-3U-R & $\begin{array}{l}\text { GGCCGCTCAGATTTACAGATAATGATGTCATTATTAAATATATATATATATATA } \\
\text { TTGTCACTCCGTTCT }\end{array}$ \\
\hline
\end{tabular}


Fig. 1

A

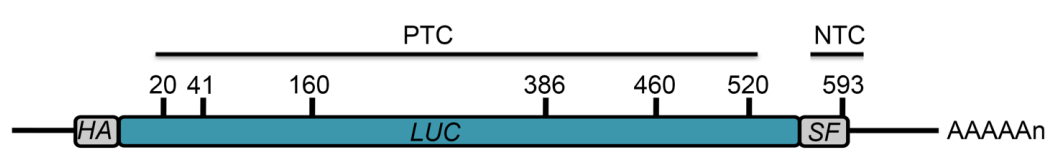

B

WT

upf1 $\triangle$

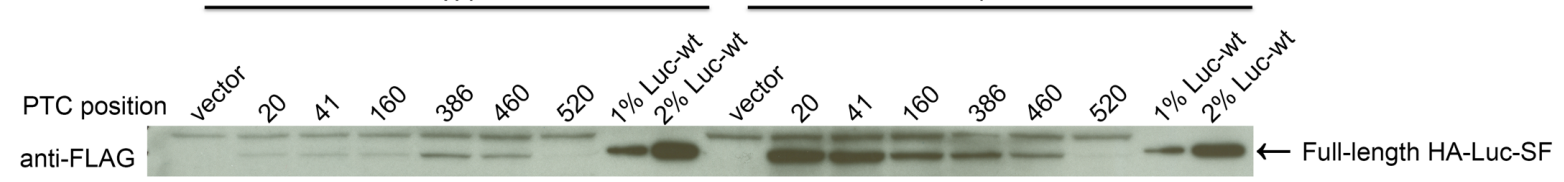
anti-FLAG

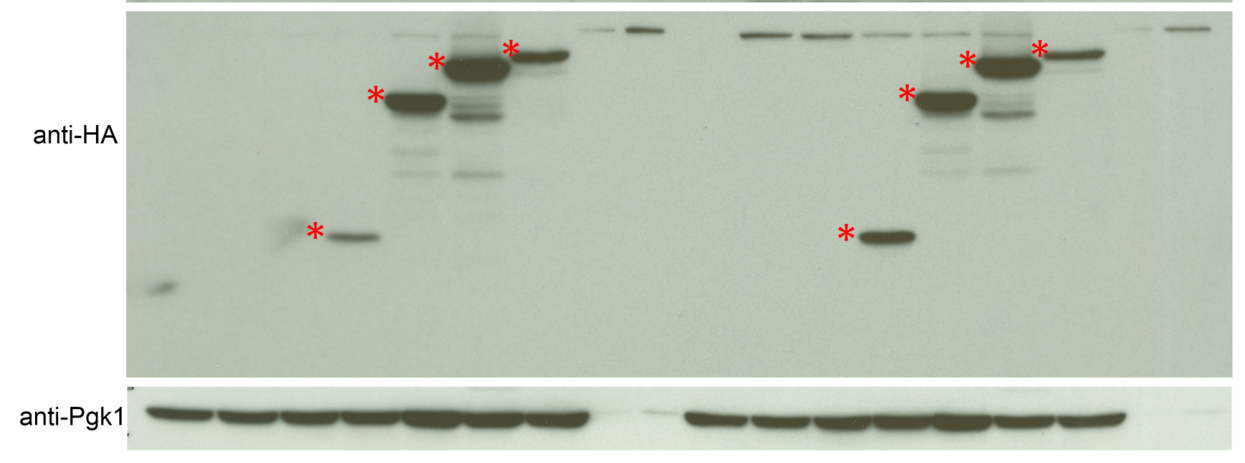

C
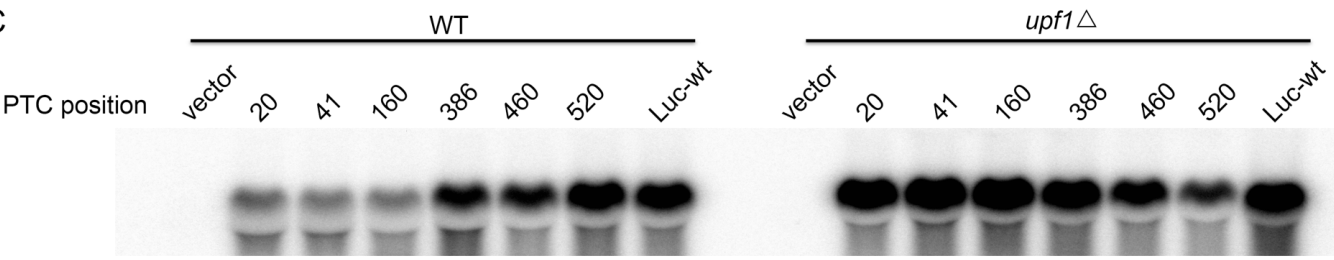

-HA-LUC-SF mRNA

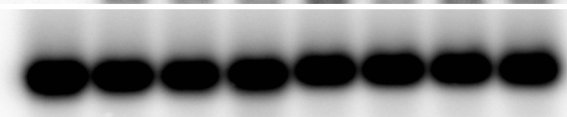

D

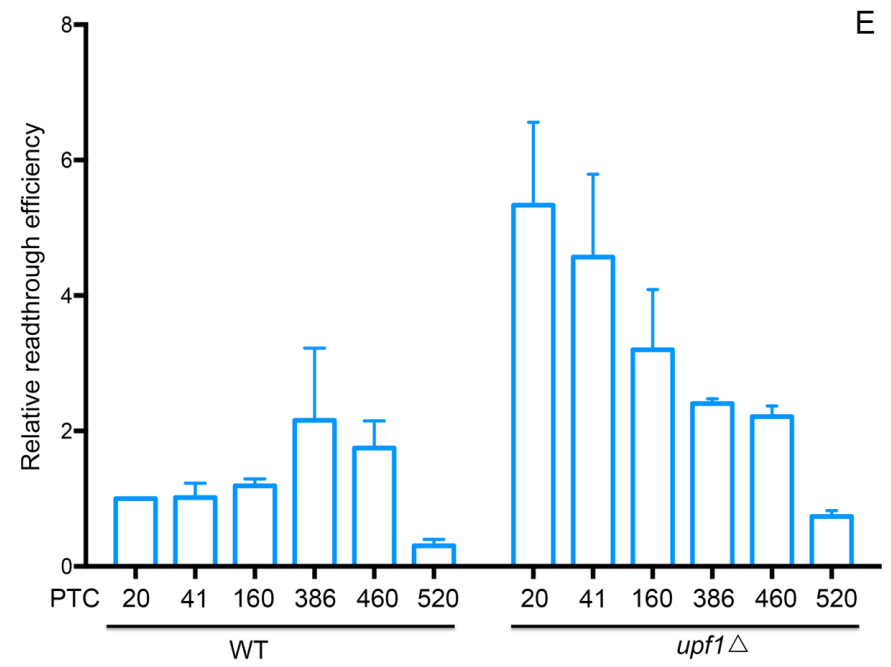

E

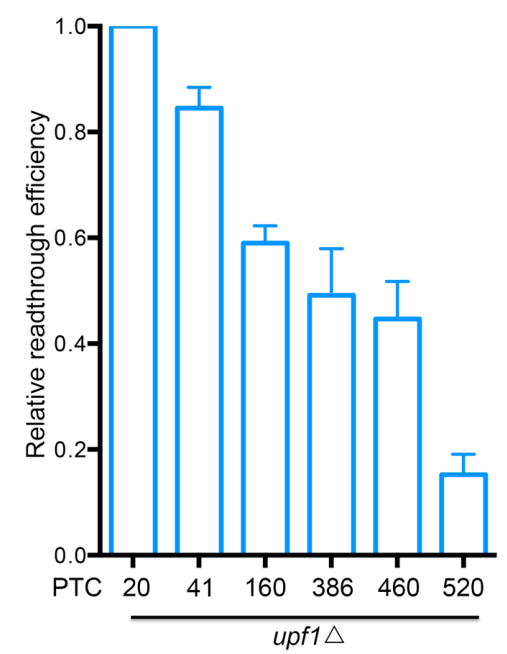


Fig. S1

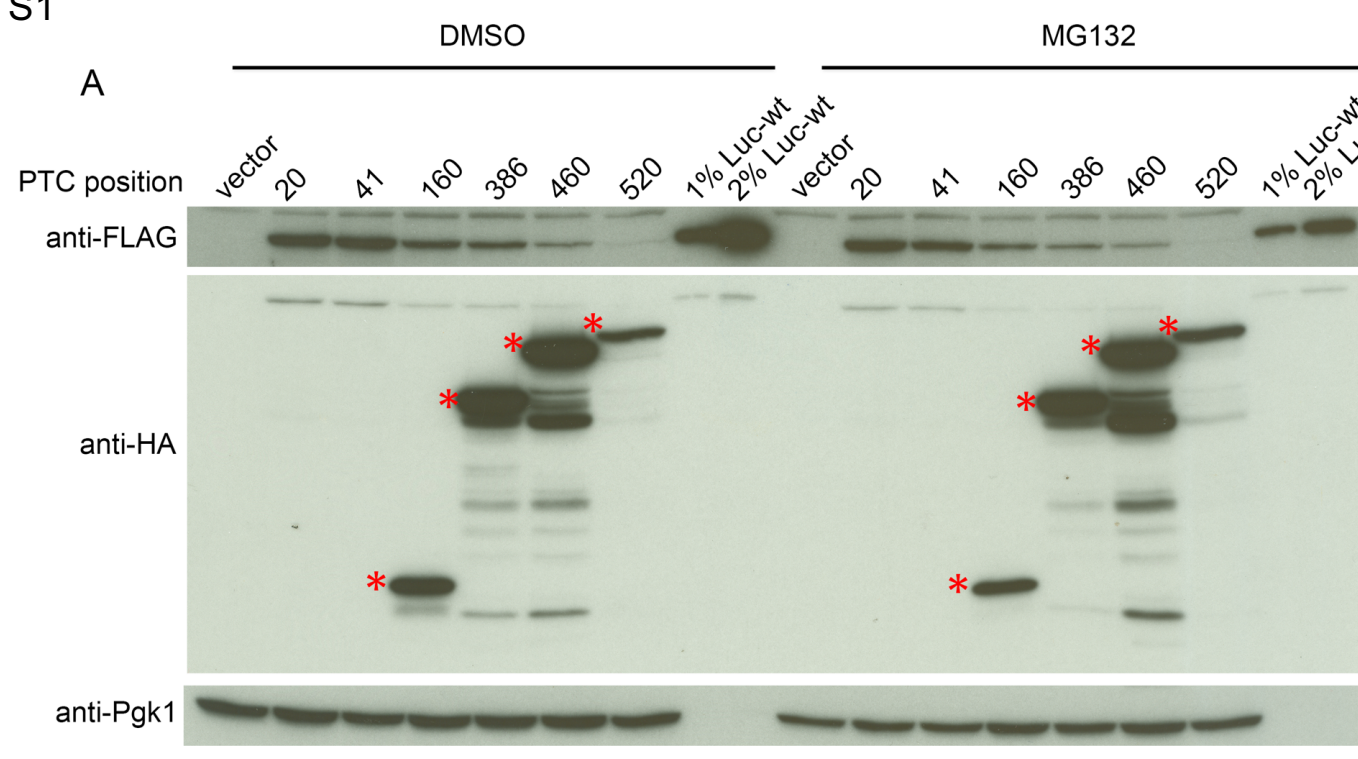

$\mathrm{B}$

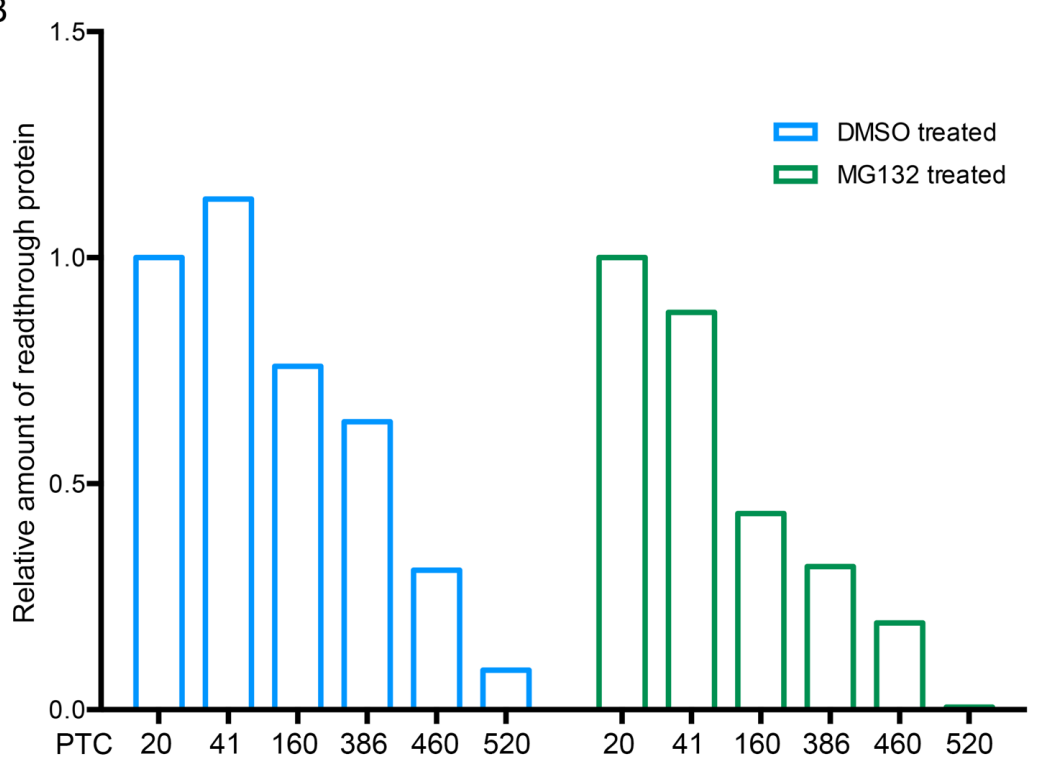

$\leftarrow$ Full-length HA-Luc-SF

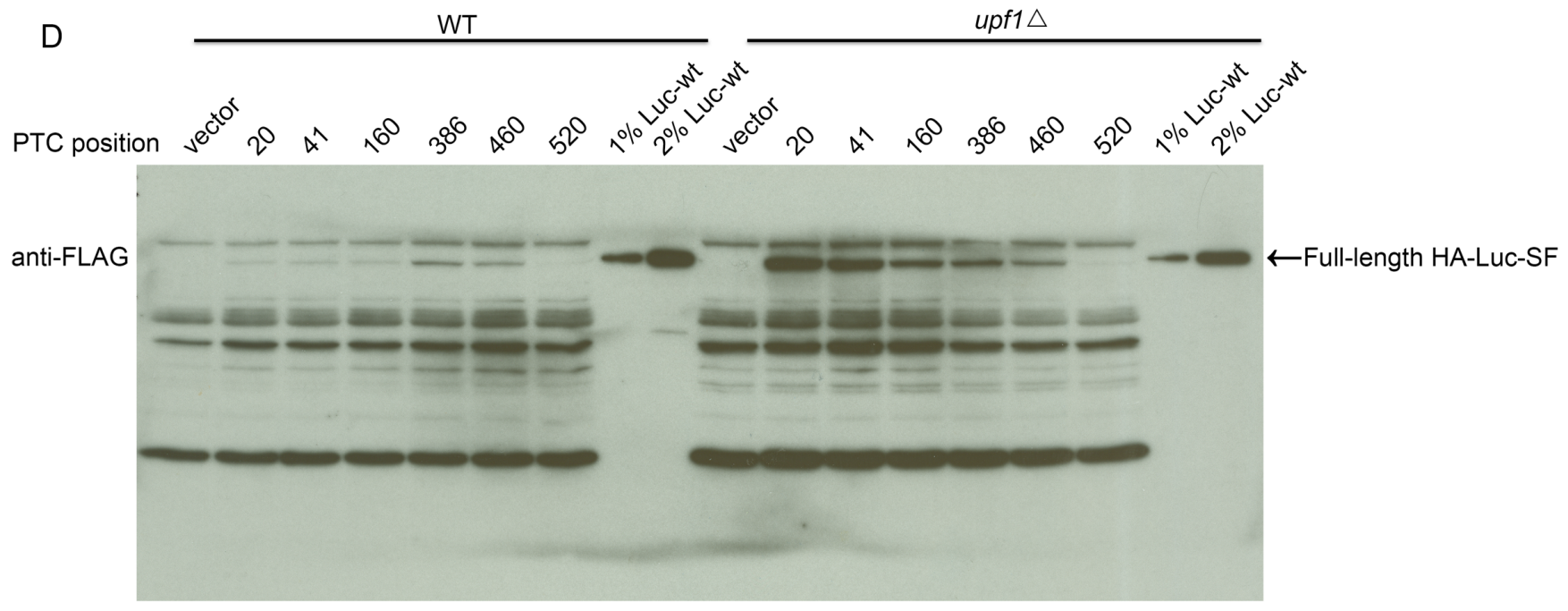


Fig. 2

A

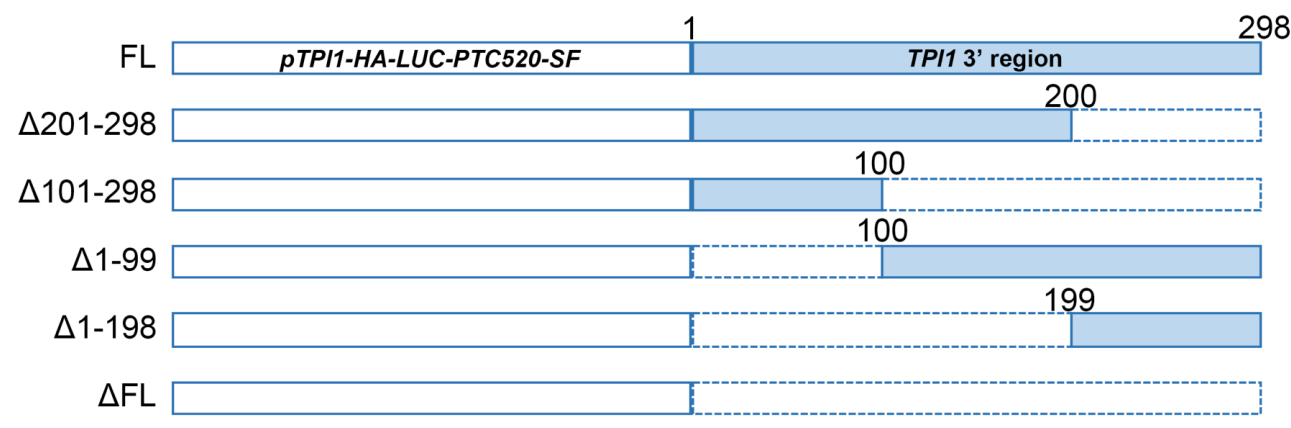

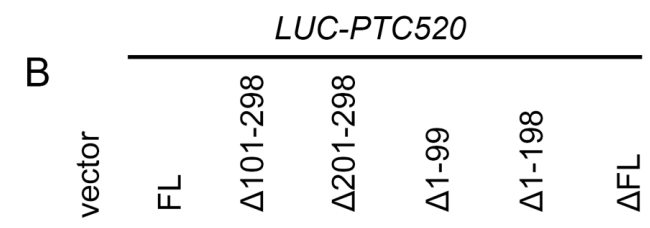
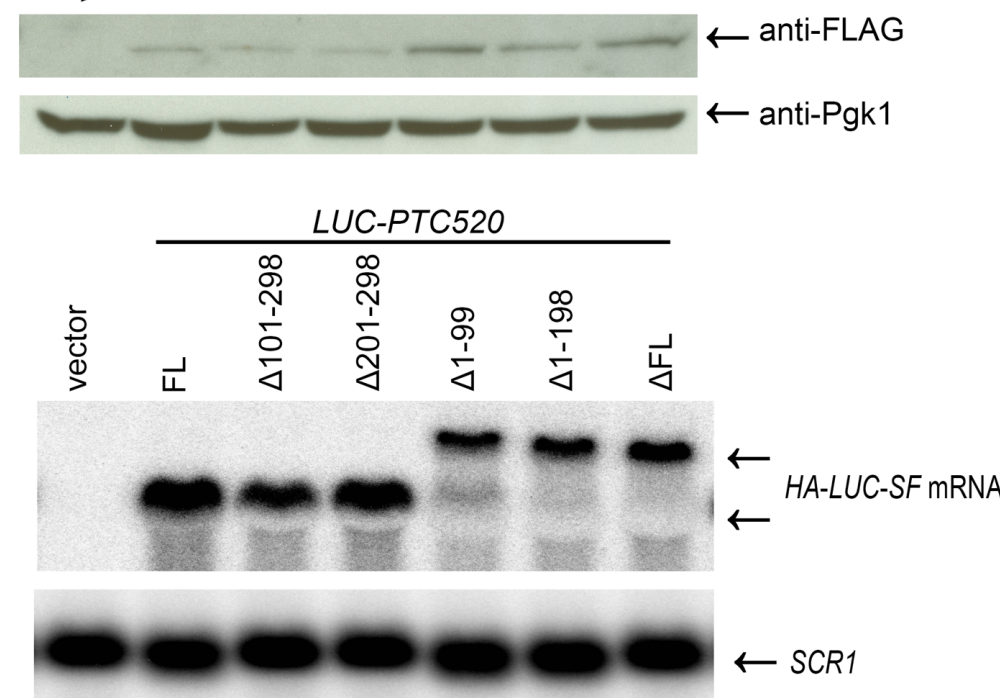

C

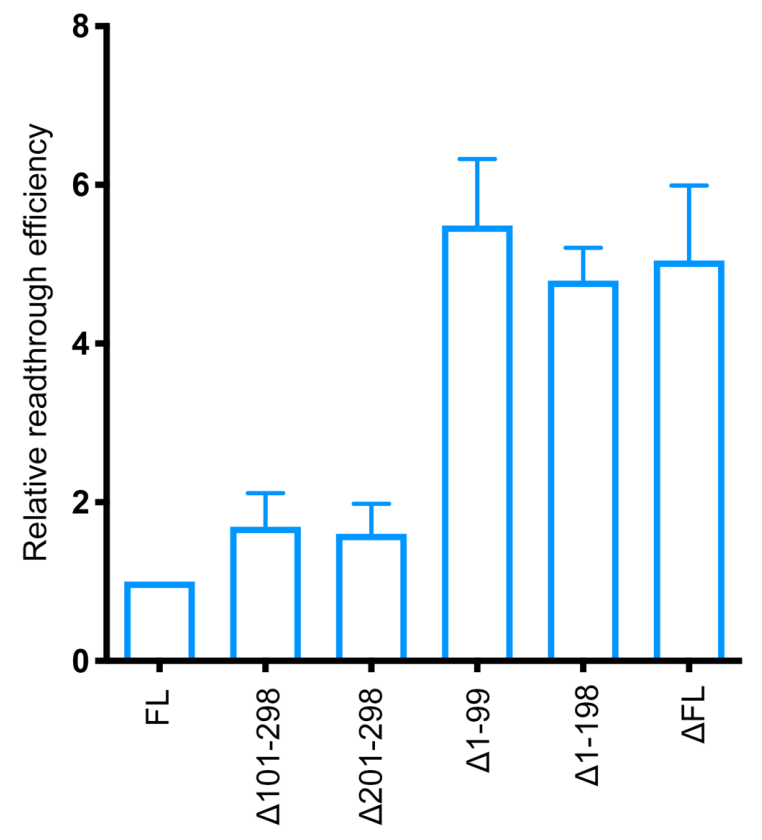

Fig. 3

A

\begin{tabular}{|c|c|c|}
\hline $\mathrm{FL}$ & PTPI1-HA-LUC-PTC52O-SF & TPI1 3' region \\
\hline & \multicolumn{2}{|c|}{25} \\
\hline$\Delta 1-24$ & & \\
\hline & \multicolumn{2}{|c|}{$24-51$} \\
\hline $25-50$ & \multirow{2}{*}{\multicolumn{2}{|c|}{51}} \\
\hline$\Delta 1-50$ & & \\
\hline
\end{tabular}

B

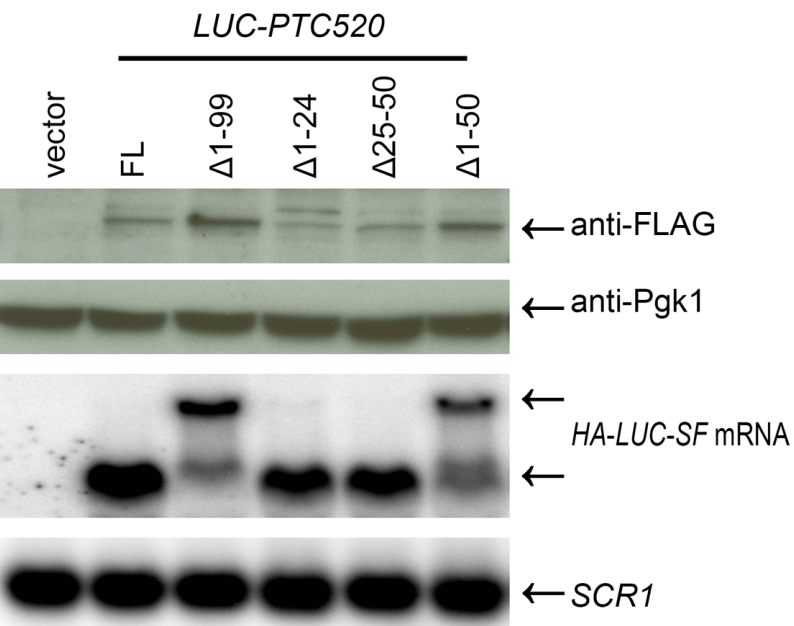

C

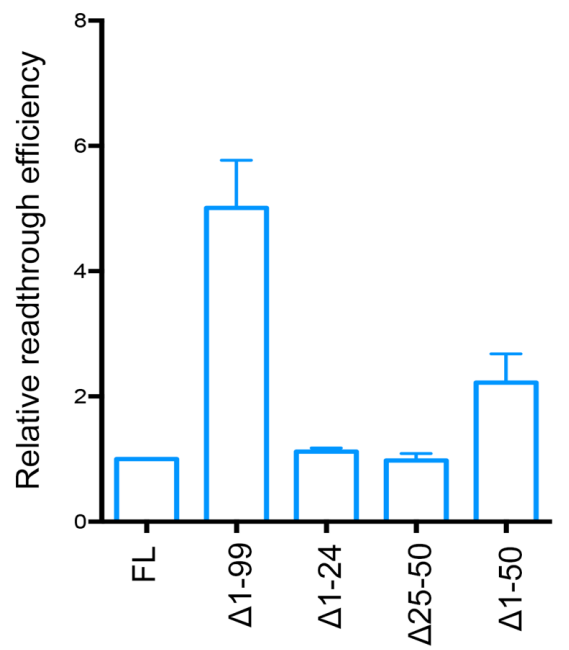


Fig. 4

A
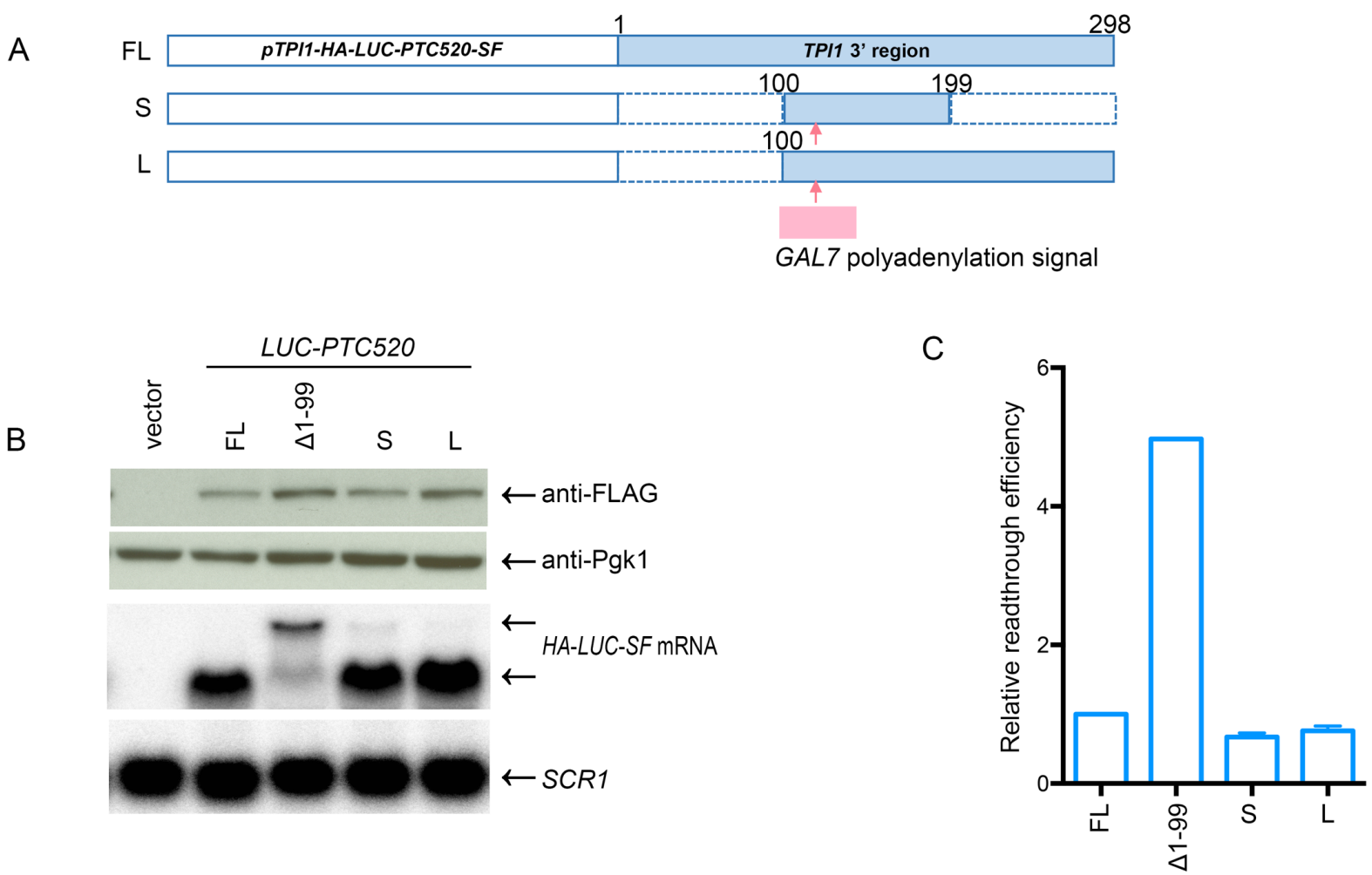

Fig. 5

A

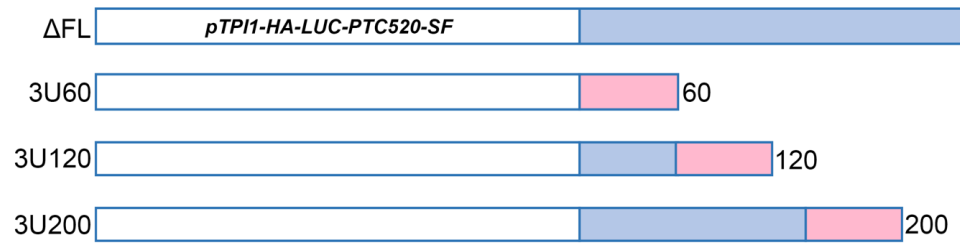

\begin{tabular}{l|l|l}
$3 \mathrm{U} 300$ & & \\
$\square$ & & \\
\hline
\end{tabular}

\begin{tabular}{l|l|l}
$3 \mathrm{U} 4000$ & & \\
\hline
\end{tabular}

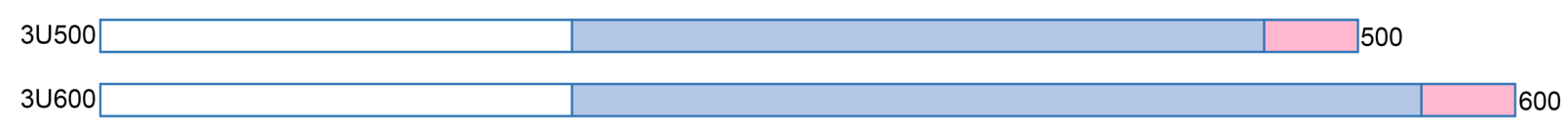

B

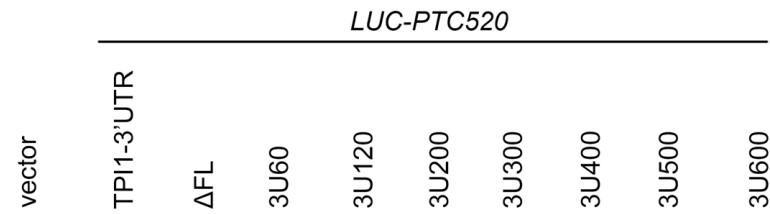

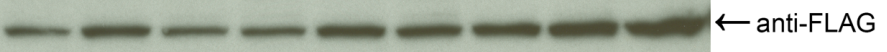
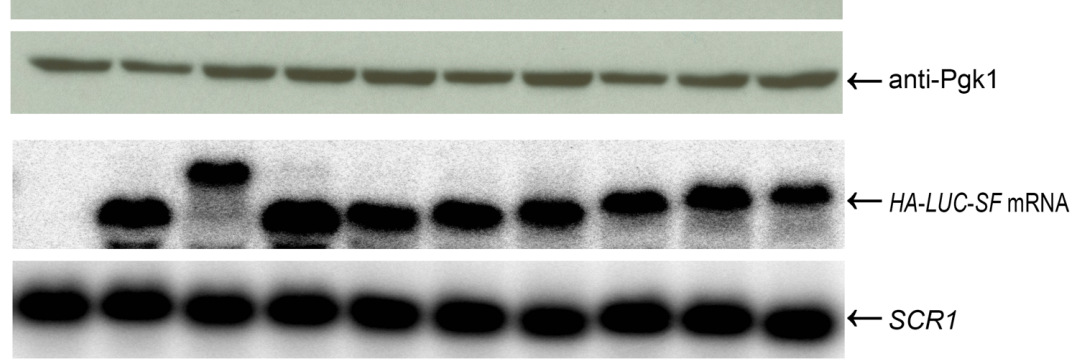

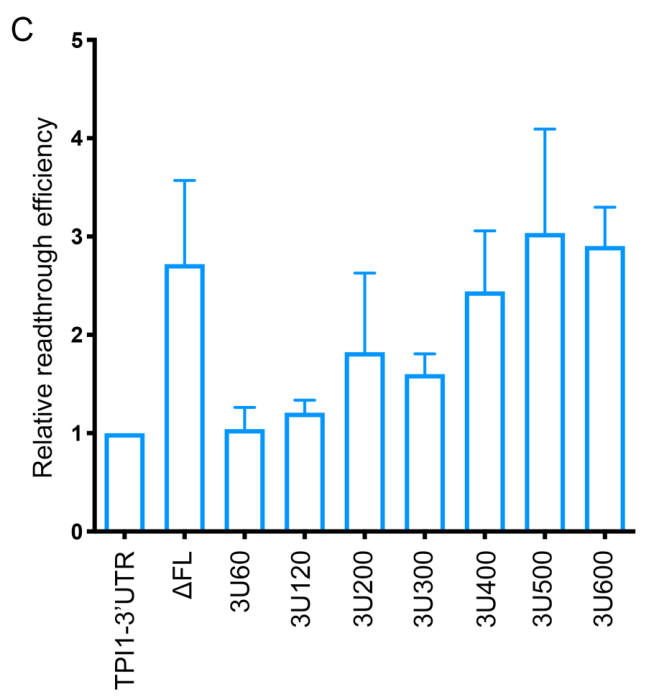


Fig. 6
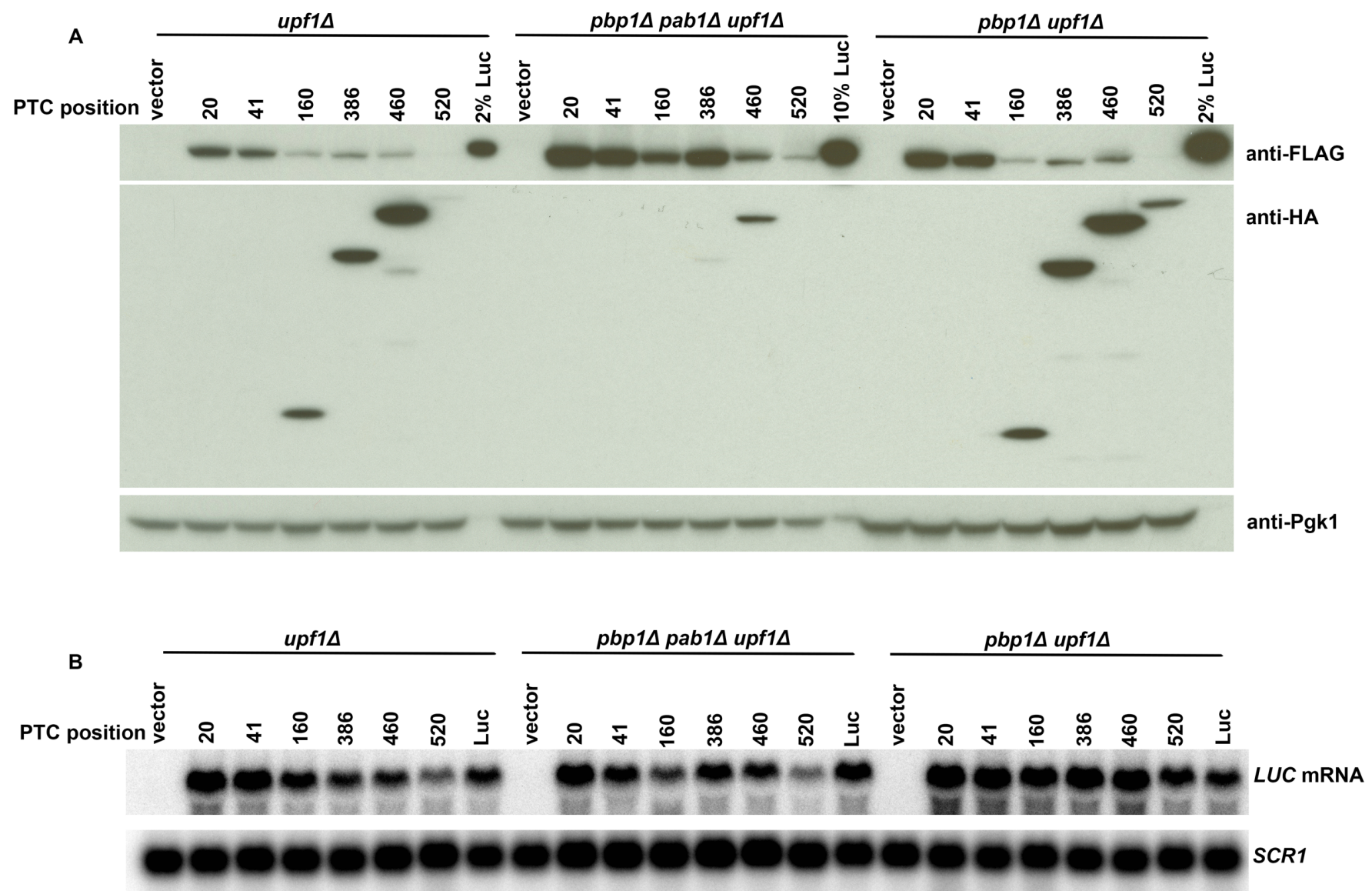

C

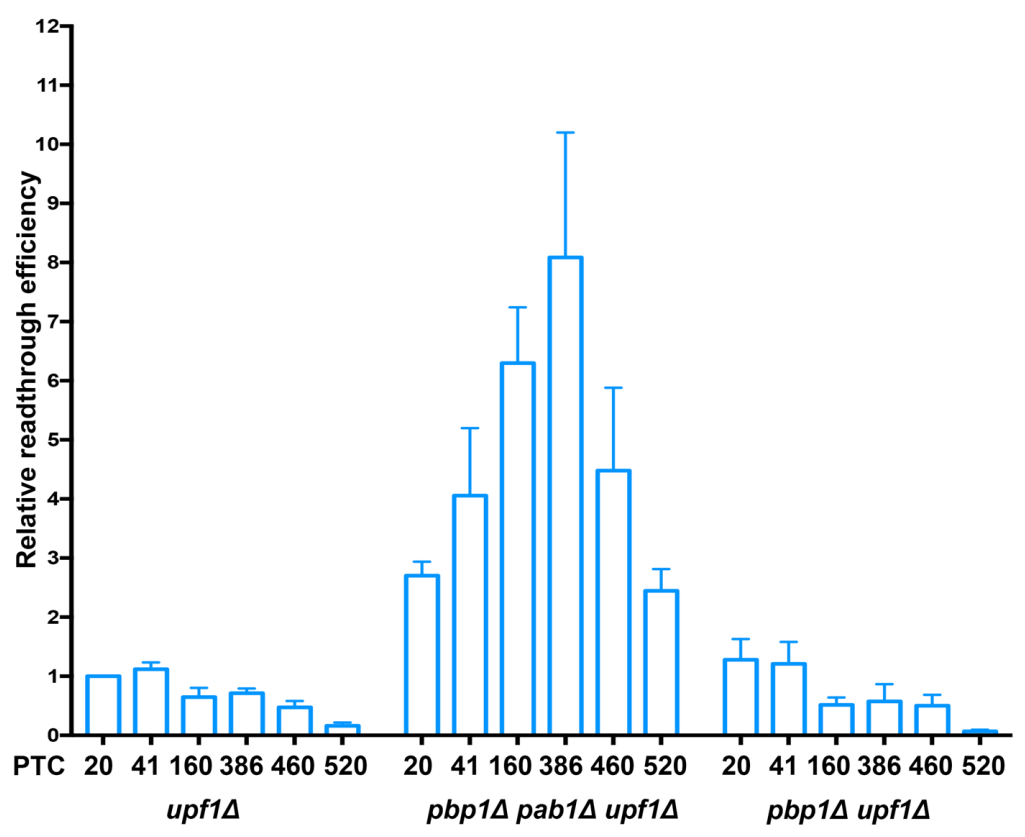


Fig. 7
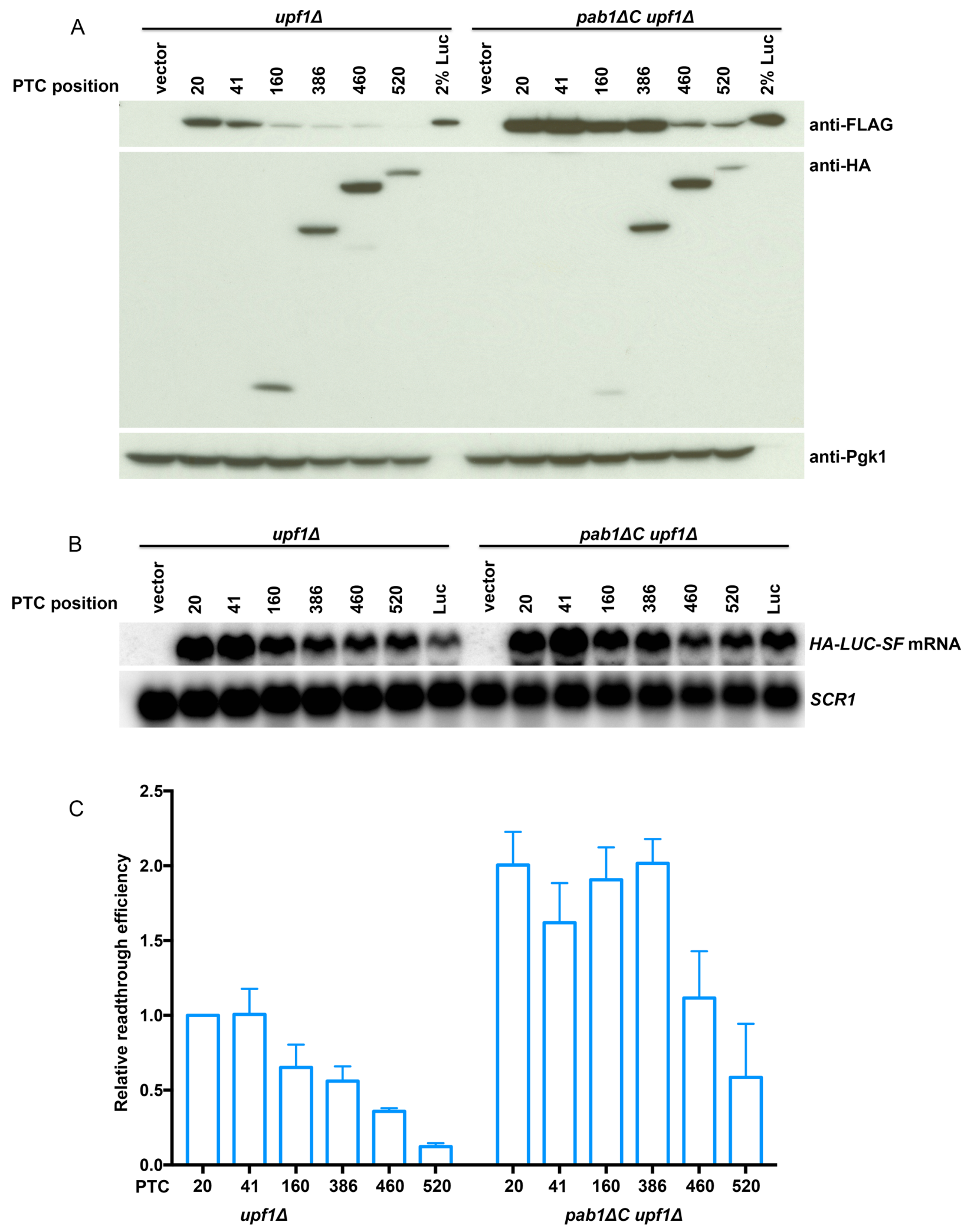
Fig. S2

A

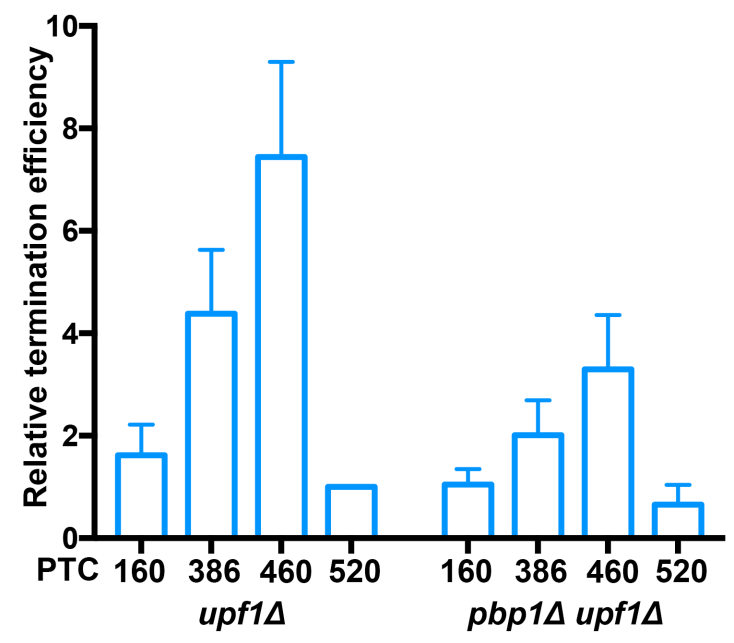

B

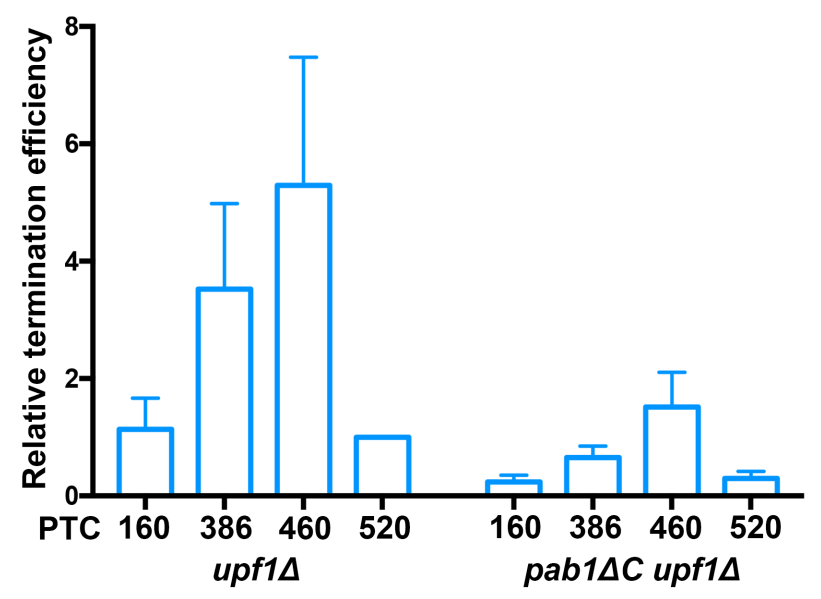

